\title{
Análise da situação da produção de etanol e biodiesel no Brasil
}

GERD KOHLHEPP

\section{Introdução}

$\mathrm{D}$ ESDE OS PRIMÓRDIOS da época colonial no Brasil, a economia brasileira foi caracterizada por ciclos econômicos de determinados produtos, como: pau-brasil, plantações de cana-de-açúcar, mineração de ouro, o boom do café (após a independência até a sua queda nos anos 1970) e a extração da borracha natural, somente no tempo da virada do século XIX para o XX.

Nos últimos 30 anos e no âmbito da modernização conservadora, a agricultura e o espaço rural passaram por mudanças estruturais básicas e economicamente bem-sucedidas embora problemáticas nos setores social e ecológico (Kohlhepp, 2003b). Os seguintes componentes reforçaram a discrepância entre fazendas com monoculturas e cash crops para exportação e minifúndios - cada vez mais marginalizados, orientados para a subsistência e o mercado interno que se dedicam principalmente ao plantio de alimentos básicos: aumento considerável das áreas cultivadas, mecanização das fazendas, sementes geneticamente modificadas e high yielding varieties, intensificação do uso de agroquímicos, enorme aumento da produtividade e modernização do processo de comercialização. As tensões sociais no espaço rural aumentaram drasticamente nos últimos anos, fazendo aumentar a violência dos atores nos conflitos rurais.

A intensa orientação para a exportação de produtos agrários como a soja, o açúcar e a laranja - como tradicionalmente o café - fez que o Brasil fosse um dos principais países exportadores de produtos agrícolas dentro da economia mundial globalizada. Desde 2006, o Brasil também assumiu a liderança nas exportações de carne e aves. Empresários com grandes capitais e concentração de propriedades estão envolvidos na rede do agrobusiness internacional e são as novas figuras-chave dos novos modelos do desenvolvimento agrário. O plantio da soja, especialmente, vive um "cortejo triunfal" até os dias de hoje.

Desde, porém, um passado recente, a problemática dos biocombustíveis ocupa o centro das atenções nacionais e internacionais em razão do aumento excessivo do preço do petróleo e da discussão mundial sobre a diminuição das emissões de $\mathrm{CO}_{2}$ e consequente diminuição do efeito estufa pelo uso de energias renováveis. Biocombustíveis são produtos à base de plantas e das quais se produz o etanol por meio do álcool da cana-de-açúcar - na Europa é produzido da beterraba - ou do amido (milho, trigo, raízes e de tubérculos). O biodiesel pode ser produzido de plantas oleosas (colza, girassol, soja, mamona e palmeira-de-dendê). 
No Brasil, a produção do carvão vegetal da madeira de eucaliptos ocupa uma área de três milhões de hectares e pertence ao grupo dos biocombustíveis que é usado na indústria siderúrgica. Esse tema como o da produção de biogás não são tratados no presente trabalho.

Para a produção de bioetanol, o Brasil conta com a cana-de-açúcar - cujas plantações passam por grande expansão no momento -, além das grandes plantações de soja e dos sítios com mamona para a produção do biodiesel. As áreas relevantes de plantio e de colheita da soja e da cana-de-açúcar para a produção de etanol e biodiesel foram muito expandidas nas últimas três décadas, especialmente nos últimos anos. Pelo aumento adicional da produtividade, as colheitas alcançaram valores recordes (figuras 1 e 2 ).

O Brasil mostra experiência de décadas na produção do biocombustível etanol extraído da cana-de-açúcar. Depois da primeira crise do preço do petróleo em 1973/1974, foi iniciado no Brasil, em 1975, o Programa Pró-Álcool para diminuir a dependência das importações do petróleo (anos 1970: $>80 \%$ da demanda; até $47 \%$ do valor da importação total do Brasil). Desde o ano de 2006, o Brasil é autossuficiente no abastecimento de petróleo, o que significa que a nova euforia para a ampliação da produção de biocombustíveis é atribuída à discussão internacional sobre a mudança do clima e às tentativas do aumento da produção de energias renováveis com consequente diminuição de emissão de $\mathrm{CO}_{2}$, visando naturalmente à enorme subida do preço da energia fóssil - o petróleo. O Brasil apresenta condições naturais extremamente favoráveis para a produção de biocombustíveis, potencial que certamente será útil para firmar seu lugar como futuro líder do etanol no mercado internacional.

O potencial do biocombustível no Brasil fortifica a sua posição como potência regional com influência global e garante a sua pretensão de líder político na América Latina. Os mais recentes desenvolvimentos no setor de biocombustíveis mostram que o Brasil passa por um processo abrangente de transformação, conduzindo não somente a enormes consequências econômicas, mas também na política interna levando a mudanças sociais, socioculturais e ecológicas. Seguem análises sobre essas questões que tangem às políticas energética, agrária, social e de meio ambiente, com base no exemplo da produção do etanol e biodiesel.

A matriz energética do Brasil apresentou, em 2006, a seguinte situação (MME, 2007): ao contrário da média global (2005:12,7\%), na produção da energia primária, as energias renováveis abrangem $47,5 \%$. Da cana-de-açúcar são produzidos 16,6\%; a energia hidráulica fornece $14,2 \%$; e a lenha, $13,5 \%$. Das energias fósseis, há a participação de $42,1 \%$ de petróleo; $8,3 \%$ de gás; e $1,1 \%$ de urânio.

Os escassos conhecimentos na Europa sobre a diferenciação das regiões naturais, econômicas e socioespaciais do Brasil, como também desconhecimento dos produtos primários na produção de biocombustíveis, como os da cana-de-açúcar e da soja, levaram alguns políticos da área energética, algumas organizações não governamentais e grande parte da imprensa daquele continente a preconceitos não diferenciados, presentes também nas discussões na Alemanha. 


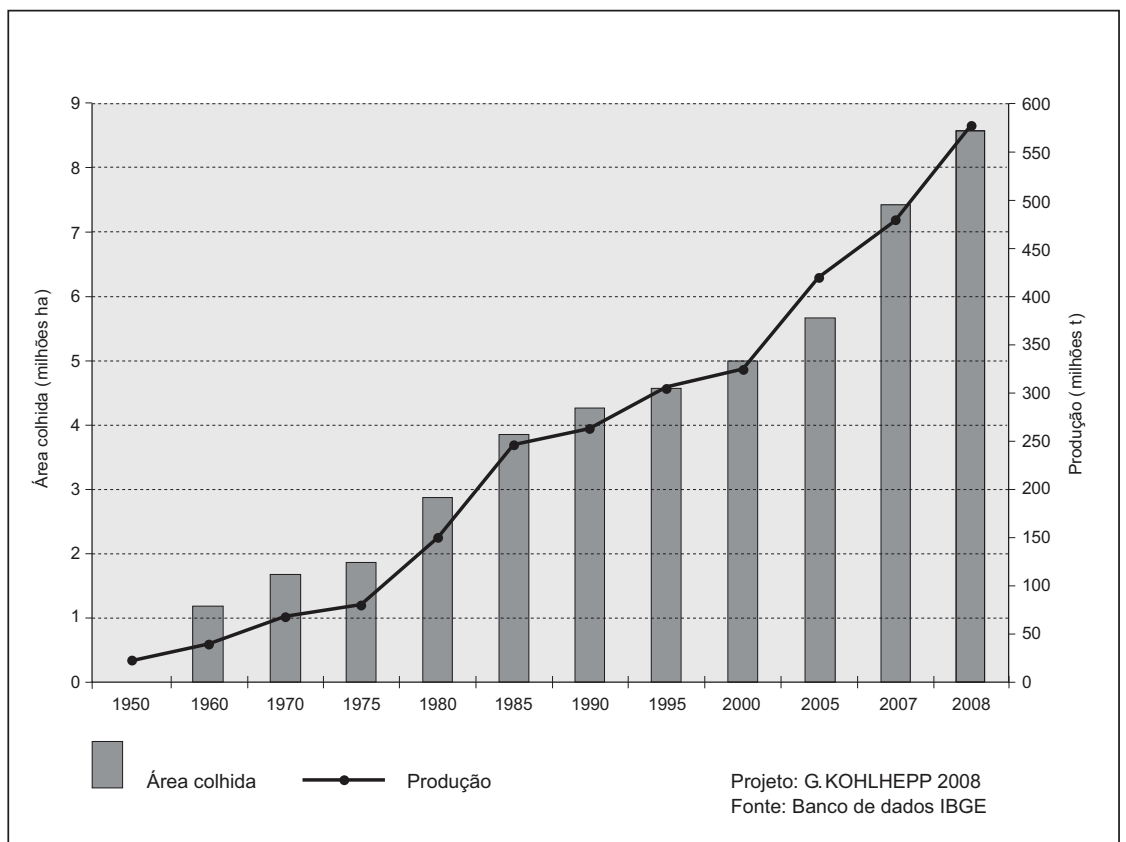

Figura 1 - Área colhida e produção de cana-de-açúcar no Brasil.

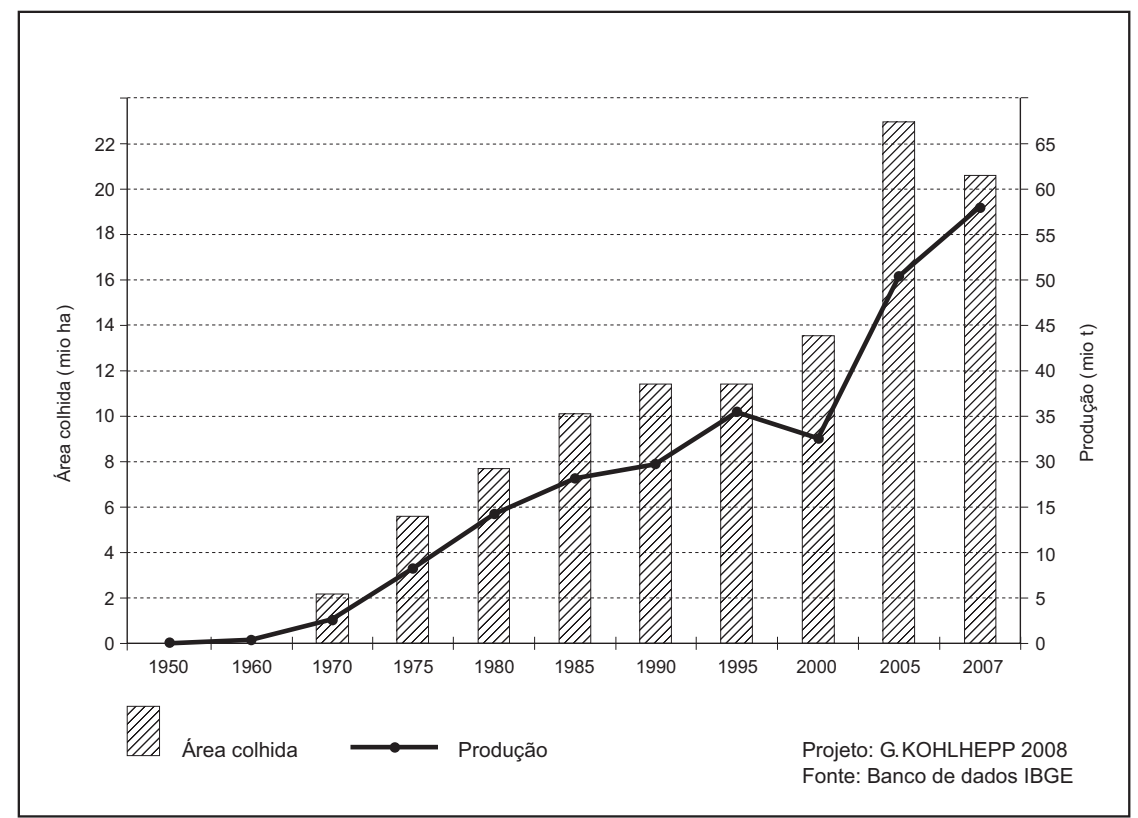

Figura 2 - Área colhida e produção de soja no Brasil.

O lobby do petróleo, de empresas de gêneros alimentícios, parte da indústria automobilística, como também produtores de biocombustíveis europeus criticam a produção de etanol no Brasil para impedir as possíveis importações do produto pela Europa, sendo esse também o objetivo de organizações não governamentais (Kobra, 2008b). 


\section{O Programa Pró-Álcool \\ para a produção de etanol (1975-1989)}

O Programa Pró-Álcool iniciado em 1975 foi concebido para garantir o fornecimento de energia, bem como para apoiar a indústria açucareira pela diversificação da produção, depois da queda do preço do açúcar em 1974. Com know-how brasileiro, foram construídas destilarias, as quais transformaram o excesso da produção de cana-de-açúcar em etanol anidro, usado como aditivo (24\%) na gasolina, sem a necessidade de nenhuma modificação nos motores dos veículos.

Durante a ditadura militar, a construção de novas destilarias foi incentivada com créditos estatais muito baratos - quase US\$ 2 bilhões (Moreira \& Goldemberg, 1999), beneficiando os grandes produtores. Por intermédio da Petrobras, não somente foram instituídos postos para venda de etanol, como também o estabelecimento do preço do produto que era vendido a preço bem mais reduzido do que a gasolina. De 1975/1976 até 1984/1985, a produção de etanol aumentou em 20 vezes (Kohlhepp, 1983) alcançando 12 bilhões de litros.

Quando, em 1979, a segunda crise do preço do petróleo agravou a situação, o Programa Pró-Álcool foi expandido (Borges et al., 1984), fazendo que, no início dos anos 1980, a produção dos motores de veículos fosse adaptada ao uso do etanol. No ano de 1984, 94,4\% dos carros novos brasileiros já eram vendidos com incentivos e créditos baratos e movidos a etanol, substituindo assim a gasolina. ${ }^{1}$ Desde 1975, registrou-se enorme expansão de áreas cultivadas com cana-deaçúcar e consequente aumento de produção. Isso sobretudo nas regiões principais de plantações em São Paulo - especialmente nos arredores de Ribeirão Preto e Piracicaba com forte expansão até 1987 (Figura 3). Em alguns municípios a área plantada com cana-de-açúcar ocupava mais de $60 \%$ da área cultivada.

Não somente se observaram crescentes monoculturas e o avanço das poderosas fazendas na acirrada concorrência pelo uso do solo, como também a ocupação das melhores terras de plantio, otimizando a produtividade. As usinas e destilarias aumentaram consideravelmente suas propriedades, enquanto o fornecimento dos pequenos e médios produtores diminuiu. Depois dos cinco anos de arrendamento aos usineiros, as terras eram vendidas pelos proprietários com grande prejuízo, pois os solos estavam gastos pelo plantio da cana-de-açúcar em monoculturas e somente poderiam ser regenerados com grandes investimentos.

Nessa época, a compra e o arrendamento de terras das destilarias estavam ligados à opressão e marginalização dos pequenos produtores de gêneros alimentícios básicos. Vínculos empregatícios seguros nas grandes fazendas foram substituídos por mão de obra barata, os boias-frias. No final dos anos 1980, a colheita em São Paulo já era mecanizada em 50\% em alguns estabelecimentos, aumentando assim o risco de desemprego e instabilidade social dos trabalhadores na época da safra.

O aumento de áreas de plantio para alimentos básicos era menor do que o crescimento da população. O plantio de tubérculos já era retrógado na segunda 
metade dos anos 1970 (Kohlhepp, 1983, Figura 1) em razão da mudança da alimentação da população, já adaptada aos costumes alimentares urbanos. Feijão e arroz tinham que ser importados pela primeira vez, aumentando o preço dos gêneros alimentícios. Mesmo nos tradicionais centros da plantação de cana-deaçúcar na Zona da Mata no Nordeste brasileiro, as áreas de plantio foram fortemente ampliadas durante o Programa Pró-Álcool.

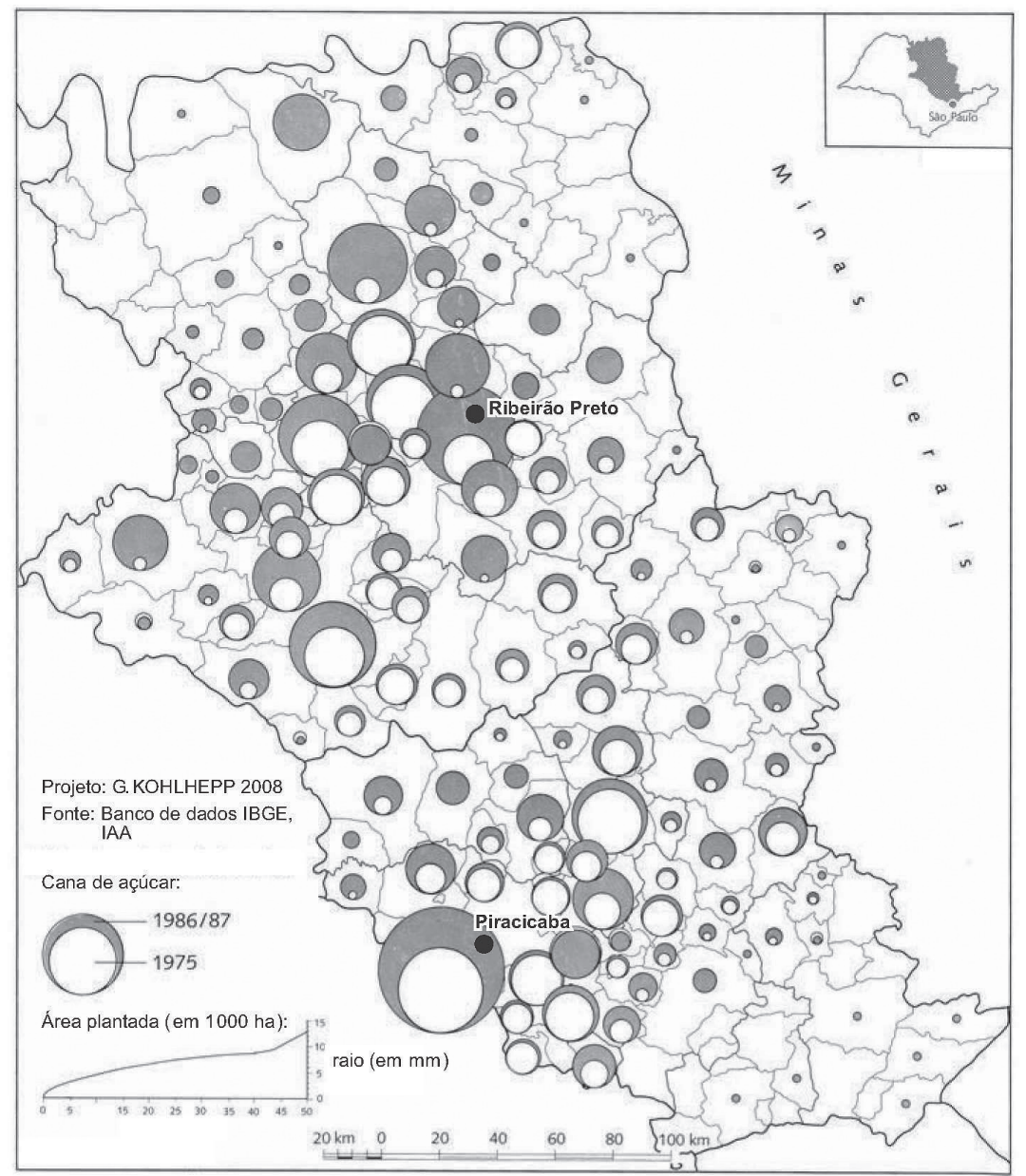

Figura 3 - Expansão da área plantada de cana-de-açúcar no nordeste de São Paulo.

São Paulo tornou-se igualmente a região de plantio de maior significado em razão do Programa Pró-Álcool. Na segunda metade dos anos 1970 e nos anos 1980 e graças às boas condições de infraestrutura, surgiu em São Paulo uma densa rede de destilarias, na maioria junto às fábricas de açúcar já existentes, especialmente no nordeste e no sudoeste do Estado. Foram instaladas inúmeras destilarias autônomas ao longo dos eixos das rodovias no oeste de São Paulo, sem ligação às fábricas de açúcar. A fabricação das instalações para destilarias concentrou-se em empresas importantes da indústria metalúrgica de São Paulo, entre outros, em Piracicaba e arredores de Ribeirão Preto. 
No auge do Programa Pró-Álcool, deu-se início à produção de etanol, extraído da mandioca, base da alimentação da população pobre do interior do país. Dos carboidratos da mandioca em forma de amido, pode ser extraído o etanol através da destilação dos substratos de glicose. Mesmo considerando que a mandioca é mais robusta que a cana-de-açúcar e está disponível todo o ano, a produtividade de etanol dessa planta sempre foi bem mais reduzida do que a do etanol produzido da cana-de-açúcar. Assim sendo, surgiu somente uma empresa modelo produzindo à base de mandioca.

Na segunda metade dos anos 1980, as subvenções para a produção do etanol tiveram que ser drasticamente reduzidas em razão da situação econômica do país e da inflação naquela época. Quando, em 1986, os preços do petróleo caíram (a US\$ 13-14/barril), o Programa Pró-Álcool, que havia se tornado rentável pelo alto preço do petróleo, acima de US\$ 40/barril, não era mais economicamente atrativo. $\mathrm{O}$ aumento do preço do açúcar e a liberalização da exportação do produto em 1988 levaram à redução da produção do etanol. Depois de 1989, com o crescente aumento do preço desse combustível, aumentaram as vendas de veículos movidos a gasolina, levando, nos anos 1990, ao final da produção de motores movidos somente a etanol.

No final do Programa Pró-Álcool, entretanto, foi mantida a mistura de etanol à gasolina de $20 \%-25 \%$, a fim de reduzir as emissões de $\mathrm{CO}_{2}$, especialmente nos centros urbanos. Os investimentos estatais para o programa de produção do etanol para motores de veículos nos setores agrário e industrial foi de US\$ 12,3 bilhões no espaço de tempo de 1975 a 1989 (Moreira \& Goldemberg, 1999).

\section{A euforia do etanol: entre a viabilidade econômica e questões de sustentabilidade social e ecológica}

Com base na discussão mundial sobre a substituição das energias fósseis por energias renováveis, no início desta década e em razão da queda do preço do açúcar no mercado mundial, o Brasil considerou a necessidade da retomada do Programa Pró-Álcool (etanol). No ano de 2002, foi apresentado o primeiro veículo com motor flex-fuel, modelo desenvolvido por empresas alemãs e produzido em série no Brasil a partir de março de 2003. Motores flex-fuel são movidos a gasolina, a etanol ou com uma mistura dos dois. Em março de 2004, 16\% dos veículos novos vendidos no Brasil já eram equipados com esse tipo de motor. Em fevereiro de 2006 já havia 76,6\% (Xavier, 2007), em novembro de 2007, 86,1\% (Olivério, 2008, ver Figura 6) e hoje mais de 92\%. Desde então, é possível fazer a escolha do tipo de combustível de acordo com o preço.

No que se refere ao fornecimento de petróleo, o Brasil é autossuficiente desde 2006, exceto no fornecimento de óleo leve. A Petrobras anunciou recentemente enormes reservas (extremamente profundas) de petróleo e gás - na região de off-shore (pré-sal) - entre o litoral do Espírito Santo e de São Paulo. Ao mesmo tempo, a procura mundial de energias alternativas, isto é, de biocombustíveis, aumentou rapidamente em razão do preço recorde do petróleo, vendido a mais 
de US\$ 140/barril (junho de 2008). Assim, o foco do interesse no Brasil, além de fatores de meio ambiente, concentra-se na estratégia da substituição da gasolina para o mercado interno, como outrora, e na chance excepcional de fornecimentos de etanol não somente para o mercado nacional, mas sobretudo e em grande escala para o mercado internacional.

O Brasil é o maior produtor (34\%) e exportador de açúcar no mundo - e também o mais barato, com uma colheita de 580 milhões de toneladas de canade-açúcar (ibidem, ver Figura 1) em 8,7 milhões de hectares (= 11,3\% de toda a área cultivada no Brasil). De 1993 até 2001, a produção de açúcar foi mais que triplicada. Segundo cálculos do BNDES, e dependendo do sucesso da exportação do etanol, espera-se para 2013 uma colheita de 700 milhões de toneladas e, para 2017, I bilhão (ibidem). Os conflitos de interesse com a produção de gêneros alimentícios podem ser evitados pelo aumento de produtividade e não pela duplicação da área cultivada.

Hoje, $55 \%$ da colheita da cana-de-açúcar, em área de 4,4 milhões de ha (= $5,7 \%$ da área cultivada no Brasil), é aproveitada para a produção do etanol, tendo aumentado muito desde 2001. Espera-se, neste ano, uma produção maior que de 21,5 bilhões de litros. O Brasil é o segundo maior produtor e consumidor de etanol (com 35\%), logo atrás dos Estados Unidos com 37\% (Xavier, 2007). Além do rápido aumento das áreas colhidas (1955: 1,0; 1977: 2,1 milhões de ha, ver Figura 1), a produtividade por hectare aumentou em 33\% desde 1977, para $75 \mathrm{t} / \mathrm{ha}$, e a produção de etanol por tonelada de cana-de-açúcar aumentou em $58 \%$ (Bertrand et al., 2008). Os números da produção em São Paulo (2008: 84 t/ha) estão bem acima da média no Brasil.

Como mostra a Figura 4, o plantio da cana-de-açúcar concentra-se fortemente no Estado de São Paulo (62\%). As plantações tradicionais no litoral do Nordeste abrangem somente $12 \%$ da área de plantio, ${ }^{2}$ e a produção do etanol, $8,9 \%$ (MME, 2006). Com 62\% e crescente tendência, São Paulo também ocupa o primeiro lugar na produção de etanol no Brasil.

No ano de 2006, três milhões de veículos leves brasileiros eram abastecidos com $100 \%$ de etanol hidratado. Até 30 de julho de 2008, já foram vendidos 6,0 milhões de automóveis ( $=20 \%$ da frota de veículos do Brasil) com motores flexfuel (Automotivebusiness, Boletim $1^{\circ}$.8.2008), isto é, eram abastecidos a gasolina (com 25\% de etanol anidro: E25) ou com a mistura de gasolina e etanol (Figura 6). As taxas de impostos para carros movidos a biocombustiveis foram então reduzidas pelo governo.

Tendo em vista a situação climática e as condições gerais de produção, a produtividade do etanol da cana-de-açúcar por ha no Brasil (6.800 litros) é quase o dobro da do etanol de milho nos Estados Unidos (3.800 litros) (Olivério, 2008). Tendo as matérias-primas uma participação de $60 \%$ dos custos, a produção do etanol no Brasil está sem concorrentes, embora não mais haja subvenções como nos tempos do Pró-Álcool. Os baixos custos de produção, que correspondem a 
aproximadamente $40 \%$ dos custos de produção por litro nos Estados Unidos, naturalmente são favorecidos pelos salários baixos que, no entanto, são mais altos no Estado de São Paulo do que os de outros setores da lavoura (ver a seguir).

Se o aproveitamento da grande quantidade dos restos do bagaço da canade-açúcar - o que já é aproveitado na produção de energia - for possível na extração do etanol, as vantagens econômicas na produção do etanol serão ainda maiores. Como o etanol tem um valor energético menor do que o da gasolina, o preço do etanol somente será economicamente interessante se não custar mais que $70 \%$ do preço da gasolina e se os grandes centros de consumo estiverem localizados nas proximidades do local de produção, como em São Paulo (Xavier, 2007).

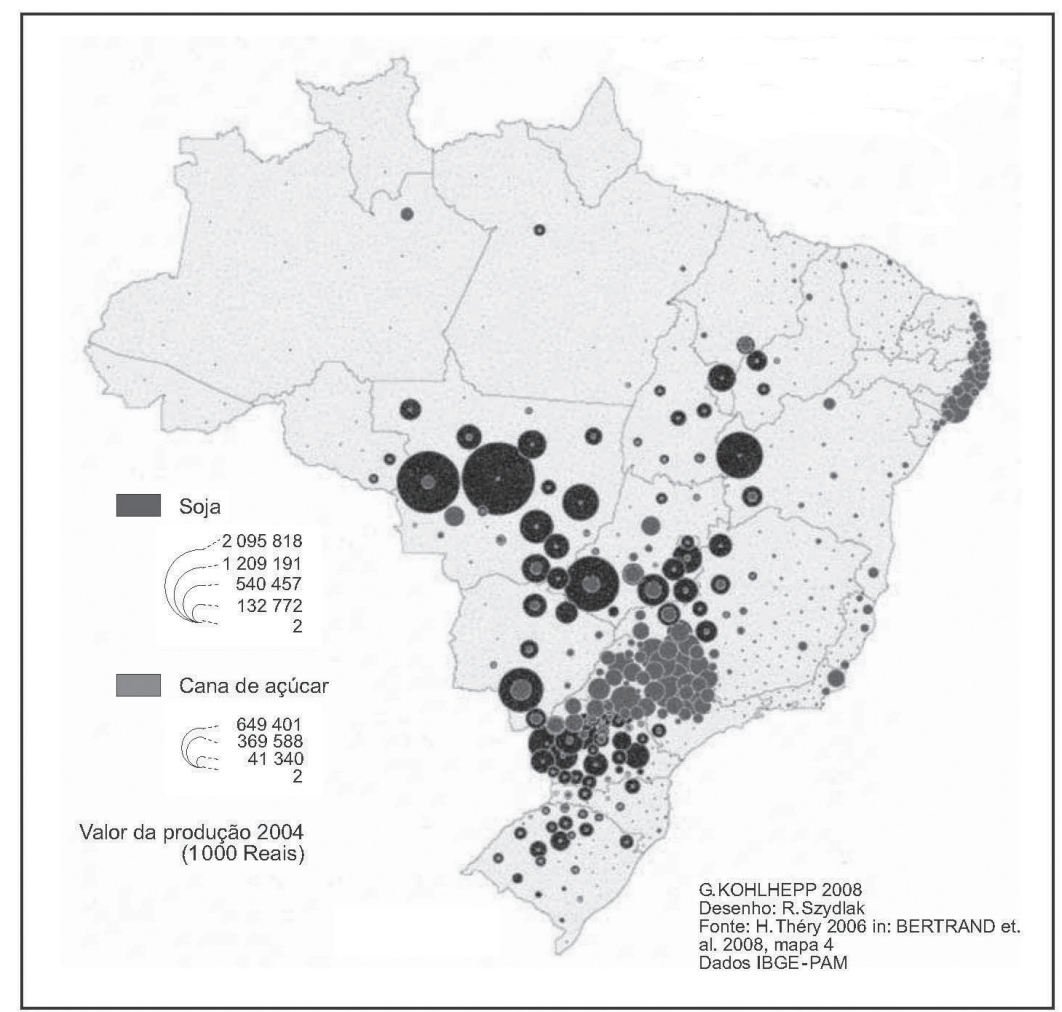

Figura 4 - Valor da produção e áreas com plantas para a produção de biocombustíveis.

Atualmente existem 359 destilarias de etanol em São Paulo, a maioria desde o Programa Pró-Álcool. Hoje, a distribuição de destilarias é como segue: 43\% em São Paulo; 9\% em Minas Gerais; 8\%, respectivamente, em Pernambuco, em Alagoas e no Paraná (Olivério, 2008), havendo tendências de descentralização para o Mato Grosso do Sul, para o Triângulo Mineiro e para Goiás (Geomapas, 2008). Com investimentos de US\$ 10 bilhões e créditos baratos do BNDES, mais 113 destilarias estavam planejadas até o ano de 2010/2011, mas somente a metade deverá ser realizada. 
O Banco Interamericano de Desenvolvimento também oferece créditos de US\$ 269 milhões para três destilarias-modelo (produtividade e sustentabilidade) em Goiás e Minas Gerais. No plano geral, calcula-se a produção de etanol até o ano de 2018 em mais de 41 bilhões de litros ( NZZ, 14, 15.6.2008). Dos postos de gasolina, 92\% dispõem de bombas de etanol para automóveis (Kersaint, 2007). Em abril de 2008, o maior produtor de etanol no Brasil (Cosan) assumiu a rede de postos de gasolina da Esso.

Num todo, o etanol representou mais da metade de todos os combustíveis para automóveis usados no Brasil em 2008.

Para a Petrobras, isso significa grande perda, mas a empresa quer investir no setor dos biocombustíveis juntamente com as empresas japonesas Toyota e Mitsui em Goiás para, posteriormente, exportar etanol para o Japão. A construção da Ferrovia Norte-Sul ajudará a escoar a produção sucroalcooleira. A montadora Toyota pretende construir "uma fábrica de alto volume de carros compactos" em Sorocaba e "a empresa mostra interesse em explorar melhor o mercado dos combustíveis alternativos" (Eubrasil, 5.8.2008). Ao mesmo tempo, a BP está investindo na produção de etanol no sul de Goiás (Folha de S.Paulo, 25.4.2008). Isso mostra o grande interesse das empresas de petróleo na participação da produção de biocombustíveis, apresentando um boom internacional de investimentos nesse setor, sobretudo porque fundos e bancos de investimentos "descobriram" a produção de biocombustíveis no Brasil.

A crise financeira que, no Brasil, aparentemente não provocou um impacto tão grande como na Europa e nos Estados Unidos reduziu, no entanto, as atividades de investimentos estrangeiros. Além disso, o preço do petróleo caiu drasticamente nos primeiros meses de 2009 , diminuindo assim a rentabilidade do etanol, rentabilidade essa que somente se inicía quando o barril de petróleo custar mais que 40 dólares. Hoje, o preço sobe novamente, atingindo $50 \%$ do máximo do ano 2008.

No Brasil, a mistura de etanol na gasolina é estipulada em $25 \%$. Na União Europeia, a mistura (hoje de $2 \%$ ) deverá ser de $5,75 \%$ de etanol (extraído da beterraba) a partir de 2012 e de $10 \%$ a partir de 2020 .

Depois da discussão sobre a mistura de etanol à gasolina na Alemanha $(5 \%$ em 2008, previsão de $10 \%$ em 2009) e da dita incompatibilidade do combustível em motores antigos, discussão da qual participaram os mais diversos lobistas, o governo cancelou, em abril de 2008, a medida precipitada do biocombustível, isto é, juntar imediatamente até $10 \%$ de etanol à gasolina. Os produtores de veículos, o Conselho de Desenvolvimento Sustentável do governo e muitas ONG não acreditam na sustentabilidade da produção do biocombustível e na certificação do produto nos países em desenvolvimento, embora no Brasil sejam construídos motores adequados ao etanol pelas filiais das indústrias automobilísticas europeias e asiáticas. Como na Europa, a produção brasileira de etanol de cana-de-açúcar frequentemente é confundida com a produção de biodiesel à base da soja, há um 
certo descrédito quanto ao balanço ecológico na produção dos biocombustíveis neste continente (ver a seguir).

No Brasil, essa posição é considerada como ação "eco-colonial" contra os países em desenvolvimento. O governo Bush planejava substituir em 20\% o consumo total de gasolina pelo etanol nos Estados Unidos até 2017. Isso significaria a demanda de 135 bilhões de litros de etanol (Kenfield, 2007), cuja maior parte somente poderia ser coberta por importação do produto e não por produção própria à base de milho, certamente um grande negócio para o Brasil. Para a produção de 1 litro de etanol de milho, nos Estados Unidos, são necessárias quase nove vezes mais energia do que na produção de etanol de cana-de-açúcar no Brasil (balanço ecológico da beterraba e do trigo na Europa: 4,5:1 [Macedo, 2007]). A produtividade por área é quase dobrada. O preço do etanol nos Estados Unidos, subvencionado com 14 cents por litro, custa 45 cents/litro, enquanto no Brasil o preço do litro de etanol não subvencionado custa 28 cents.

A exportação brasileira de etanol perde a vantagem na competição em razão das altas taxas de importação dos Estados Unidos (US\$ 0,54 por galão $=3,8$ litros). Apesar disso, o Brasil exporta $70 \%$ da demanda mundial do etanol que corresponde a apenas 19\% de sua produção, como em 2006. Cinquenta e oito por cento do total exportado é destinado aos Estados Unidos. Na questão do biocombustível, os dois países têm interesses políticos e econômicos em comum. A visita do presidente Bush ao Brasil, em março de 2007, não somente fortificou a posição política regional do Brasil na América do Sul, mas também mostrou o interesse de cooperação tecnológica pela carta de intenção de São Paulo (Nolte \& Stolte, 2007). Mediante a cooperação dos dois países no desenvolvimento de tecnologias e incentivos à produção de biocombustívies, a influência do presidente Chávez nesta região poderia ser abafada - além disso, diminuiria a dependência do petróleo pelos Estados Unidos. Para o Brasil, a redução das taxas de importação e a crescente e rápida demanda, não satisfeita pela própria produção, poderiam significar a abertura de grande mercado para biocombustíveis nos Estados Unidos.

O Japão, que também não possui áreas suficientes para o plantio de matériaprima para a produção de biocombustíveis, intenciona misturar pelo menos $10 \%$ de etanol à gasolina e ficará dependente de importação em grande escala.

\section{Aparte: Preconceitos na Europa e realidade no plantio da cana-de-açúcar e da produção de etanol no Brasil}

A entrada de etanol no mercado europeu continua difícil e o Brasil espera até hoje sem resultados - maiores concessões nesse setor. Entretanto, a discussão sobre o assunto na Alemanha e em outros países europeus é conduzida de forma não objetiva com base em informações errôneas, imputações e atividades de imprensa de grupos lobistas.

1. A repetida afirmação nas mídias sobre a destruição das florestas tropicais na Amazônia por causa da expansão do plantio da cana-de-açúcar é falsa. 
Isso vale para o avanço em forma direta, tendo em vista que as áreas atuais de plantio e as áreas potenciais de expansão encontram-se muito distantes das florestas tropicais da Amazônia (Figura 5), com exceção das remotas possibilidades de plantio no futuro, em solos degradados no Maranhão. As destilarias de etanol que, em razão do processo de produção, têm que estar localizadas junto às áreas de plantio da cana-de-açúcar também dependem economicamente da proximidade dos mercados.

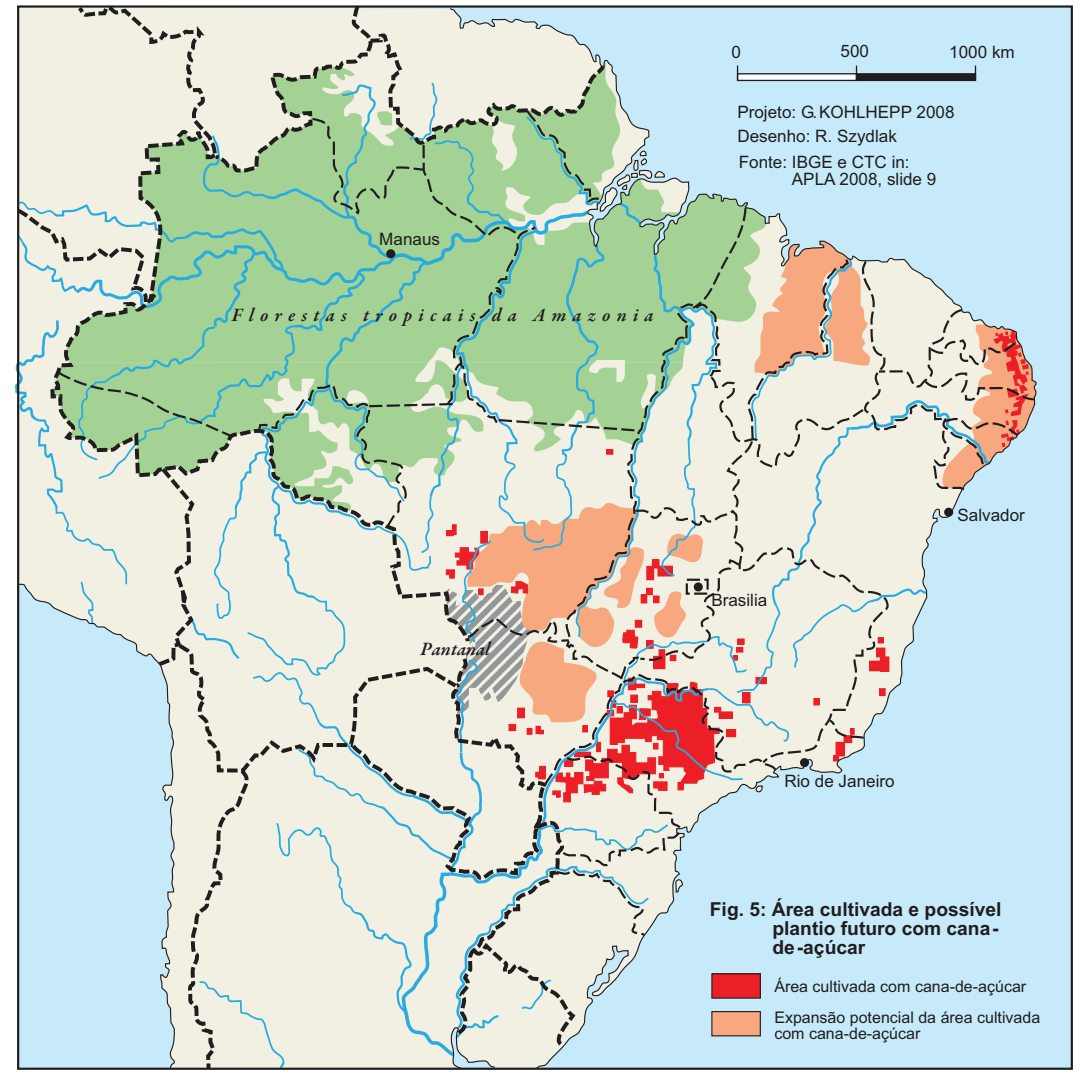

Figura 5 - Área cultivada e possível plantio futuro com cana-de-acúcar.

Certo é que o plantio da soja e a consequente produção de biodiesel à base de soja ameaçam seriamente a floresta tropical.

A ameaça indireta à floresta tropical pelo plantio da cana-de-açúcar também não tem fundamento. A afirmação de que a expansão do plantio da cana-de-açúcar nos campos cerrados desloca a pecuária local para o Norte e com isso para as florestas tropicais não é correta nem lógica sob ponto de vista econômico. Infelizmente, desde os anos 1970, há pecuária em pastos nas derrubadas na Amazônia (Kohlhepp, 1981, 1987), em razão da política de subvenções. Nos campos cerrados, cuja vegetação natural já está reduzida a $20 \%$ em razão da agricultura (Macedo, 2005), o número de gado por área poderá ser aumentado facilmente com o melhoramento dos pastos: em vez de criar uma cabeça de gado em 2 ha, seria possível criar uma 
cabeça por 0,7 ha (média em São Paulo). Isso mostra que, com uso reduzido de área, a pecuária pode ser conduzida muito mais eficientemente do que nas pastagens na floresta tropical - que também é climaticamente desfavorável. Além disso, ainda há abrangentes áreas nos campos cerrados (área total: 180 milhões de ha = $21,7 \%$ do território brasileiro) apresentando qualidades diversas de solos.

Segundo dados do IBGE, a área dos estabelecimentos agropecuários abrange 355 milhões de ha, isto é, $42 \%$ da área nacional.

\begin{tabular}{|lrcc|}
\hline Área cultivada & 76,7 milhões de ha & $21,6 \%$ do total \\
de soja & 20,6 " & " & $5,8 \%$ \\
de milho & 14,0 " & " & $4,0 \%$ \\
de cana-de-açúcar & 8,7 & " & $2,5 \%$ \\
cana para etanol & 4,4 " & $1,3 \%$ \\
outras culturas & 33,4 " & $9,3 \%$ \\
& & & \\
Pastagens & 180 milhões de ha & $50,7 \%$ \\
Mata & 98,3 milhões de ha & $27,7 \%$ \\
\hline
\end{tabular}

Deve ser alertado expressamente de que com isso não é possível estabelecer critérios quanto à qualidade de solo, condições climáticas (áreas áridas da caatinga no sertão no Nordeste do Brasil), tampouco afirmações sociais específicas. Será essencial estabelecer em que região haverá expansão do plantio da cana-de-açúcar, quais restrições de plantio e imposições de zoneamento em nível municipal serão adotadas (ver a seguir) e se áreas de proteção ao meio ambiente, parques e reservas continuarão a ter realmente proteção definitiva.

Mais problemático ainda é a expansão do plantio da cana-de-açúcar - como o já existente da soja - atingindo exatamente as áreas fronteiriças da planície do Pantanal. Por meio de agroquímicos, lixo industrial e esgoto dos povoamentos, vindos de regiões mais altas, são levados pelos rios para o Pantanal e ameaçam em grande escala as características ecológicas e a biodiversidade (Kohlhepp, 1995).

2. A crítica geral feita ao Brasil de usar áreas de plantio para a produção de etanol ao invés de cultivar alimentos também não é correta - crítica essa certamente aplicável a alguns países da Ásia do Sul e Sudeste em razão da situação de concorrência nestes países quanto à expansão irresponsável de áreas para a produção de biocombustíveis.

O tema foi generalizado pelo relator da ONU, Jean Ziegler, em abril de 2008, e a crítica ao Brasil é incorreta em seu balanço total, ao contrário do que na época do Programa Pró-Álcool, entre 1975 e final dos anos 1980 (Kohlhepp, 1983). Deve ser mencionado o deslocamento de pequenos colonos para áreas menos favorecidas na época do Programa Pró-Álcool, com liquidação de inúmeras pequenas propriedades e consequente redução da produção de alimentos. Hoje 
é bem diferente. O Brasil apresenta vantagens também nesse caso em razão das grandes áreas ainda disponíveis para a agricultura.

A posição marcante de empresas multinacionais de gêneros alimentícios, que outrora não assumiam atitudes quanto à fome nos países em desenvolvimento, deve ser analisada mediante a política agrária dos países industrializados, cujas subvenções agrárias e produtos de exportação dificultam a agricultura nos países do Terceiro Mundo. A produção do etanol do milho, como nos Estados Unidos, e de cereais, como em parte na Europa, faz aumentar demasiadamente o preço desses alimentos. Isso levou à "crise da tortilla" no México (Suhr, 2008), pois o preço do milho aumentou exorbitantemente no México por causa das estratégias na produção de biocombustíveis nos Estados Unidos.

A drástica subida dos preços dos alimentos básicos, também no Brasil, deve ser atribuída especialmente ao aumento do preço do petróleo, dos combustíveis, adubos, pesticidas e custos de transporte (Schmidhuber, 2008), como também pela especulação nos mercados de capitais e não pela diminuição de áreas de plantio, muito menos por causa da diminuição da produção ou por aumento de consumo de gêneros alimentícios. O problema central concentra-se na falta do poder aquisitivo das classes sociais baixas.

O grande aumento das plantações da cana-de-açúcar em São Paulo de 1,8 milhão de hectares (em 1990) para 4,6 milhões (em 2008) é atribuído, em grande parte, ao forte recuo das áreas de pasto de mais de 2,5 milhões de hectares nesse espaço de tempo (Tabela 1$)^{3}$. A atual redução de áreas de plantio de gêneros alimentícios em São Paulo foi enormemente compensada pela alta produtividade. Apesar da diminuição de mais ou menos $50 \%$ da área de plantio do feijão, entre 1990 e 2008, a quantidade da produção subiu em 16\%. Com a diminuição da área de plantio do milho em 14\%, a produção aumentou em 78\%, em razão da duplicação da produtividade (Tabela 2 ). ${ }^{4}$

Tabela 1 - Plantio, produção e produtividade no Estado de São Paulo

\begin{tabular}{|c|c|c|c|c|c|c|c|}
\hline & \multicolumn{2}{|c|}{ Área plantada } & \multicolumn{2}{|c|}{ Produção } & \multirow{2}{*}{\multicolumn{2}{|c|}{$\frac{\text { Produtividade }}{\text { (t/ ha) }}$}} \\
\hline & & (1.000 ha) & Índice & Índice & (Milhões t) & & \\
\hline \multirow[t]{5}{*}{$\begin{array}{l}\text { Cana-de- } \\
\text { açúcar }\end{array}$} & 1990 & 1.836 & 100 & 139,4 & 100 & \multicolumn{2}{|c|}{75,9} \\
\hline & 2000 & 2.491 & 136 & 189,4 & 136 & \multicolumn{2}{|c|}{76,0} \\
\hline & 2008 & 4.597 & 250 & 391,9 & 281 & \multicolumn{2}{|c|}{85,3} \\
\hline & & \multicolumn{2}{|c|}{ Pastagens naturais } & \multicolumn{2}{|c|}{ Pasto } & \multicolumn{2}{|c|}{ Total } \\
\hline & & (1.000 ha) & Índice & (1.000 ha) & Índice & (1.000 ha) & Índice \\
\hline \multirow[t]{3}{*}{ Pastagens } & 1990 & 2.383 & 100 & 7.798 & 100 & 10.181 & 100 \\
\hline & 2000 & 1.637 & 69 & 8.432 & 108 & 10.069 & 99 \\
\hline & 2008 & 1.176 & 49 & 6.467 & 83 & 7.643 & 75 \\
\hline
\end{tabular}

Compilação: Gerd Kohlhepp. Fonte: www.iea.sp.gov.br (2009). 
Tabela 2 - Área plantada, produção e produtividade em São Paulo

\begin{tabular}{l|c|c|c|c|c|c}
\hline \multirow{2}{*}{ Gêneros } & Anos & \multicolumn{2}{|c|}{ Área plantada } & \multicolumn{2}{c|}{ Produção } & Produtividade \\
\hline & & $(1.000$ ha $)$ & Índice & $\begin{array}{c}\text { Milhões de } \\
\text { sacos }\end{array}$ & Índice & sacos \\
\hline Feijão & 1990 & 338 & 100 & 4,48 & 100 & 13,3 \\
\hline & 2000 & 199 & 59 & 4,32 & 96 & 21,7 \\
\hline & 2008 & 169 & 50 & 5,20 & 116 & 30,8 \\
\hline & & & & & & \\
\hline Milho & 1990 & 1.061 & 100 & 45,1 & 100 & 41,7 \\
\hline & 2000 & 1.111 & 103 & 57,8 & 128 & 52,0 \\
\hline & 2008 & 935 & 86 & 80,4 & 178 & 86,0 \\
\hline Soja & 1990 & 561 & 100 & 15,6 & 100 & 27,8 \\
\hline & 2000 & 534 & 95 & 19,9 & 128 & 37,3 \\
\hline & 2008 & 445 & 79 & 20,4 & 131 & 45,8 \\
\hline
\end{tabular}

Compilação: Gerd Kohlhepp. Fonte: www.iea.sp.gov.br (2009).

Tabela 3 - Plantio de gêneros alimentícios no Brasil

\begin{tabular}{|c|c|c|c|c|c|c|c|}
\hline & & $\begin{array}{c}\text { Área plantada } \\
\text { (em } 1.000 \text { ha) }\end{array}$ & Índice & $\begin{array}{l}\text { Produção } \\
\text { (em } 1.000 \text { t) }\end{array}$ & Índice & $\begin{array}{c}\text { Produção } \\
\text { (kg/ha) }\end{array}$ & Índice \\
\hline \multirow[t]{3}{*}{ Arroz } & 1990 & 4.159 & 100 & 7.421 & 100 & 1.880 & 100 \\
\hline & 2000 & 3.705 & 89 & 11.135 & 150 & 3.038 & 162 \\
\hline & 2006 & 3.999 & 96 & 13.193 & 178 & 3.369 & 179 \\
\hline \multirow[t]{3}{*}{ Feijão } & 1990 & 5.304 & 100 & 2.234 & 100 & 421 & 100 \\
\hline & 2000 & 4.441 & 84 & 3.056 & 137 & 688 & 163 \\
\hline & 2007 & 3.976 & 75 & 3.169 & 142 & 797 & 189 \\
\hline \multirow{3}{*}{ Milho } & 1000 & & 100 & & 100 & 1071 & 100 \\
\hline & 2000 & 12.648 & 105 & 32.321 & 151 & 2.718 & 145 \\
\hline & 2007 & 14.064 & 117 & 51.846 & 243 & 3.751 & 201 \\
\hline \multirow[t]{3}{*}{ Mandioca } & 1990 & 1.976 & 100 & 24.322 & 100 & $12,3 \mathrm{t}$ & 100 \\
\hline & 2000 & 1.737 & 88 & 23.044 & 95 & $13,3 \mathrm{t}$ & 108 \\
\hline & 2007 & 1.941 & 98 & 26.541 & 109 & $13,7 \mathrm{t}$ & 111 \\
\hline \multirow[t]{3}{*}{ Batata } & 1990 & 159 & 100 & 2.234 & 100 & $14,1 \mathrm{t}$ & 100 \\
\hline & 2000 & 152 & 96 & 2.607 & 117 & $17,2 \mathrm{t}$ & 122 \\
\hline & 2007 & 147 & 93 & 3.551 & 160 & $24,2 \mathrm{t}$ & 172 \\
\hline
\end{tabular}

Compilação: Gerd Kohlhepp. Fonte: IBGE e www.ipeadata.gov.br (2009). 
Entre 1990 e 2006/2007 e em âmbito nacional, as áreas de plantação de arroz $(-4 \%)$, feijão $(-25 \%)$, mandioca $(-2 \%)$ e batata $(-7 \%)$ diminuíram, e a produção dos gêneros alimentícios básicos como o feijão e o arroz aumentou consideravelmente em razão do aumento da produtividade - de 42 e $78 \%$ (Tabela 3). Nesse mesmo espaço de tempo, a área de plantio do milho aumentou em $17 \%$, a produção aumentou em 143\%, havendo duplicação da produtividade. ${ }^{5}$

A conclusão é de que o aumento do plantio da cana-de-açúcar não causou escassez de gêneros alimentícios - muito pelo contrário -, houve grande aumento da produção dos gêneros alimentícios mais importantes com base no melhoramento da produtividade.

3. Como terceira e principal crítica é a não credibilidade à sustentabilidade da produção de biocombustíveis no Brasil.

Hoje, o assunto deve ser visto diferenciadamente. Assim é constatado que, nas últimas duas a três décadas, isto é, desde a época do Programa Pró-Álcool, a situação trabalhista salarial dos colhedores e cortadores foi melhorada consideravelmente, bem como a proteção ao meio ambiente no plantio da cana-de-açúcar e na produção de etanol nas principais áreas de São Paulo. Macedo (2005) alerta para o fato de que são usados menos adubos, pesticidas e inseticidas do que nas plantações de café, algodão e laranjas - também em comparação com outros países com plantio de cana-de-açúcar. Hoje, mais de $75 \%$ da área de cana no Brasil não necessita de nenhuma forma de irrigação. Já nas culturas de cana, são usados mais herbicidas do que nas culturas antes mencionadas.

Em estudo das universidades de Utrecht e da Unicamp sobre a sustentabilidade da produção de etanol no Brasil (Smeets et al., 2006), é salientado que a produção de etanol em São Paulo corresponde aos critérios de sustentabilidade da Holanda. A Holanda já inicou a venda de etanol brasileiro, e a mistura (hE15 biosuper) contém $15 \%$ de etanol, misturado à gasolina. De acordo com estudos recentes, podem ser adicionados até $22 \%$ de etanol à gasolina ${ }^{6}$ em carros europeus sem motor flex.

A situação relativamente favorável de São Paulo não se aplica a todas as áreas de plantio da cana-de-açúcar, especialmente às do Nordeste do Brasil. As consequências ecológicas das grandes monoculturas da cana-de-açúcar (ver a seguir) continuam a causar problemas. É valido mencionar que, outrora, os lobistas agrários europeus, que agora exigem veemente a sustentabilidade na produção de biocombustíveis, não questionavam a problemática ecológica do plantio nas importações de pellets de soja, usados como ração, ou na importação de concentrado de laranjas. Mesmo na luta de concorrência no mercado açucareiro mundial (beterraba contra cana-de-açúcar), esse argumento até agora não teve relevância para os produtores e consumidores europeus.

4. A crítica aos itens principais feita pelas organizações não governamentais 
ao Acordo Energético Alemanha-Brasil (Kobra, 2008b), em maio de 2008, é “artificial".

Para a análise atual da situação, a junção de preconceitos ideológicos à política energética é extremamente antiprodutiva (problemática da energia nuclear), bem como a generalização de argumentos não relevantes para o Brasil e somente parcialmente válidos para a produção de etanol e para as regiões principais de produção (como a destruição da floresta tropical, gasto excessivo de água, escassez de alimentos, trabalho escravo etc.).

Está claro que a sustentabilidade do plantio e da produção de etanol tem que ser certificada quando das exportações para a Europa e para os Estados Unidos - ver as atividades objetivas da Holanda. Assim, o Acordo entre o Brasil e a Alemanha focaliza os principais objetivos, isto é, importações de biocombustíveis do Brasil serão possíveis desde que assegurada a sustentabilidade dos produtos. Esse procedimento será mais fácil no caso do etanol do que do biodiesel. É importante ressaltar que o Acordo exigirá maiores esforços do Brasil quanto ao cumprimento dos critérios ecológicos e sociais na luta global de concorrência.

Com ações internacionais acentuadas, o presidente do Brasil está trabalhando no sentido de expandir as parcerias de política energética no âmbito das relações Sul-Sul, sobretudo na África, mas também nos países da América Central, para fortalecer o perfil internacional com estratégias próprias de energia (Mildner \& Zilla, 2007).

O governo brasileiro está muito interessado em estabelecer o etanol como commodity no mercado mundial. Em 2007, o Brasil associou-se ao Fórum Internacional de Biocombustíveis - uma iniciativa que conta com a participação dos Estados Unidos, da China, da Índia, da África do Sul e da União Europeia. Nesse fórum, são discutidas as normas internacionais dos biocombustíveis, procuradas soluções para os problemas de infraestrutura e de logística e garantias de fornecimento, bem como o estabelecimento de um programa comum de ação para o uso de biocombustíveis em outros países (Silva, 2007).

Além do norte (Barretos e Orlândia) e do oeste de São Paulo (Assis, Presidente Prudente), Minas Gerais (Triângulo Mineiro), sudoeste de Goiás e sul de Tocantins, a expansão atual do plantio da cana-de-açúcar atingirá o norte do Paraná, Mato Grosso do Sul e o sul de Mato Grosso, onde estão sendo construídas novas destilarias e muitas outras já se encontram em planejamento (Bertrand et al., 2008; Geomapas, 2008). Para 2011, está planejada a conclusão de uma pipeline de etanol de $1.150 \mathrm{~km}$ de comprimento de Goiás até o porto de São Sebastião em São Paulo. Isso diminuirá o preço de transporte do etanol em 30\%, comparado com o custo do transporte por caminhão. Outros pipelines já estão projetados.

Na Região Amazônica, existem poucos plantios de cana-de-açúcar - mas somente em áreas periféricas e degradadas de antigas áreas da floresta tropical. 
O ex-governador do Acre, membro do partido do presidente Lula e a quem se atribuiu consciência com o meio ambiente, iniciou a produção do "álcool verde", construindo uma destilaria (Kobra, 2007; Fatheuer, 2007). Não há na região nenhuma outra produção de etanol de relevância. Nas áreas tradicionais de plantio, há possibilidades de expansão e consequente aumento de produtividade, como também alternativas espaciais nos campos cerrados (ver o Aparte), de modo que a expansão de plantio da cana-de-açúcar não significaria aumento de atividades destruidoras na Amazônia.

Há um prognóstico geral de que, segundo planejamento existente, as áreas de plantio da cana-de-açúcar aumentarão até o ano de 2012 em 3,6 milhões de ha. Essa seria uma área adicional de plantio com tamanho aproximado da Suíça e teria aspecto negativo do ponto de vista de meio ambiente quando se tratar de monoculturas em regiões ecologicamente sensíveis.

As consequências ecológicas de plantio excessivo da cana-de-açúcar são chamadas de "deserto verde" pelos grupos ambientalistas e os fenômenos são conhecidos desde os anos 1990. A enorme expansão de monoculturas sufoca toda e qualquer biodiversidade. $\mathrm{O}$ uso de agrodefensivos pulverizados por aviões apresenta ainda um grande problema de saúde, assim como a queimada controlada de parte das áreas. Em 80\% das áreas de plantio, ainda é adotado esse procedimento, provocando, muito frequentemente, doenças nas vias respiratórias e enormes emissões de $\mathrm{CO}_{2}$, além de espalhar o "carvãozinho", limpeza do qual é gasto enorme volume de água.

Em São Paulo, esse tipo de queimada será permitida até o ano de $2021 \mathrm{com}$ colheita mecanizada e até 2031 em outras regiões (Noronha \& Ortíz, 2006). A mecanização de colheitas, adotada voluntariamente, está aumentando rapidamente, e as queimadas certamente deixarão de ser feitas entre os anos 2014 e 2017. O uso da vinhaça (restos líquidos na destilação da cana-de-açúcar) na ferti-irrigação (Macedo, 2007) deverá reduzir o uso de adubos artificiais, mas polui fortemente os lençóis d'água. No entanto, esses restos da destilação não mais são conduzidos diretamente aos ribeirões com tanta frequência.

Parece que, até então, não se fez uso de sementes geneticamente modificadas nas plantações de cana-de-açúcar. Mas sabe-se que nos laboratórios já é realizada pesquisa sobre as sementes transgênicas.

Em razão da situação social, as condições de trabalho em muitas plantações de cana-de-açúcar são problemáticas. Os cortadores, com contrato temporário, vindos do Nordeste e de Minas Gerais, têm que cortar em média 10-12 t/dia em São Paulo (2007: 6-15 t/dia em Ribeirão Preto), enquanto nos anos 1980 eram exigidos 5-8 t/dia (Kenfield, 2007). Para 12 horas de trabalho/dia em uma semana de seis dias, são pagos em São Paulo até 320 euros/mês, e o salário real por tonelada de cana-de-açúcar diminuiu. ${ }^{7}$ Segundo Macedo (2005), o salário médio pago para atividades nas plantações da cana-de-açúcar no Brasil é de R \$ 495; no Nordeste R\$ 316; mas em São Paulo, R\$ $810(1$ euro = R\$ 2,54). 
Em Pernambuco, em 1993, 25\% dos colhedores tinham entre 7 e 17 anos de idade ${ }^{8}$ - crianças e jovens que ajudavam os pais a garantir determinada quantidade de colheita. O número atual de crianças que trabalham em colheitas felizmente diminuiu consideravelmente. Inúmeros casos de doença em adultos, por exaustão de trabalho, lamentavelmente, ainda são registrados todos os anos.

Ainda hoje, $70 \%$ da colheita da cana-de-açúcar, no Brasil, é feita manualmente. Com isso, 982 mil pessoas encontravam um trabalho temporário em 2008. A constante ameaça dos grandes produtores de mecanizar a colheita impede o aumento justo dos salários. Especialmente em São Paulo, há grande tendência para uma rápida mecanização - atualmente em 55\%. No entanto, a mecanização total causaria uma catástrofe social. Em Ribeirão Preto, a "capital do agrobusiness", no centro das plantações da cana-de-açúcar, vivem hoje milhares de pessoas em favelas.

Nas enormes monoculturas, há um mínimo de trabalhadores por hectare (0,1 trabalhador/ha, média anual - comparado a 1,5 trabalhadores/ha nos sítios de pequenos produtores), provocando, algumas vezes, o fim da vida econômica nas pequenas cidades onde a infraestrutura não mais pode ser sustentada. No exemplo de Pradópolis (15 mil habitantes), mostra-se que existem tentativas positivas de "como conciliar cana, desenvolvimento social e ecologia" (Veja, 23.7.2008, p.29). Pela prosperidade econômica obtida com a produção de açúcar e de etanol, foi possível realizar, nesse pequeno município, uma boa infraestrutura e uma gestão pública responsável, reduzir a taxa de analfabetismo e de mortalidade infantil, e requalificar a maioria dos antigos boias-frias com cursos profissionalizantes. Assim, o choque do desemprego causado pelo aumento da mecanização na colheita da cana-de-açúcar foi bem mais ameno. A redução das queimadas nas áreas de plantio da cana-de-açúcar foi uma grande contribuição ao meio ambiente. Segundo a União da Indústria de Cana-de-Açúcar (Unica), inúmeros projetos sociais são hoje realizados em São Paulo com o objetivo de melhorar as condições de vida dos trabalhadores, aumentando assim a responsabilidade dos produtores (Embaixada do Brasil, 2007). ${ }^{9}$

Infelizmente, as condições em outras regiões do país são muitas vezes piores do que em São Paulo. A imprensa alerta constantemente para as condições escravizantes de trabalho, quase sempre fora de São Paulo, que são averiguadas pelas autoridades, mas em poucos casos levam à punição.

Inúmeros protestos de ONG e ações dos Movimento dos Sem Terra (MST) são realizados em São Paulo, com consequentes acampamentos nas rodovias e ocupações de terras. O líder do MST, José Rainha Jr., disse que a ocupação de 12 fazendas é uma ação de alertar o governo sobre a falta de uma reforma agrária e os problemas sociais ligados à expansão da cana-de-açúcar ( O Estado de S. Paulo, 20.2 2007). O suicídio em público de um ambientalista em Campo Grande mostra a luta desesperadora contra a temida ocupação dos arredores do Pantanal pelos interesses do etanol do agrobusiness, no Mato Grosso do Sul. 


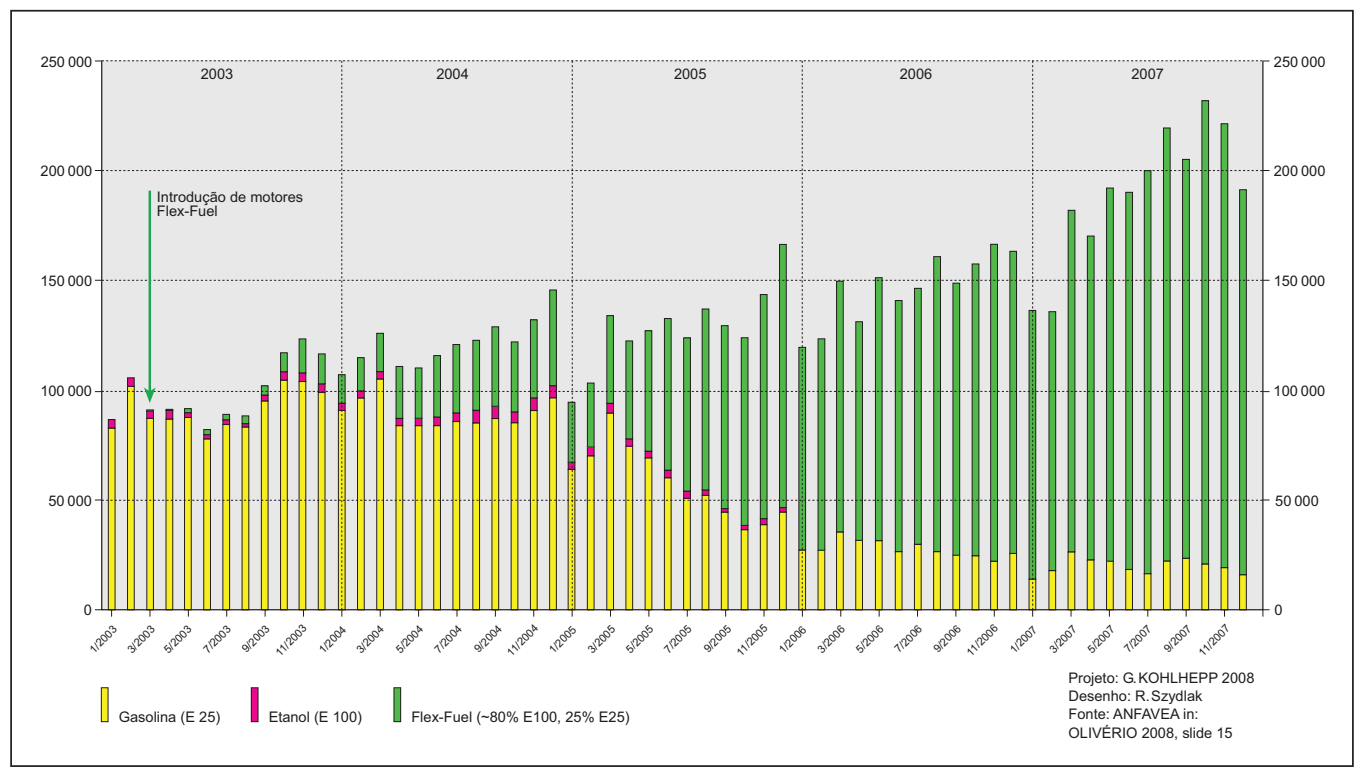

Figura 6 - Uso de combustível nos carros 0 km no Brasil, 2003-2007.

O foro brasileiro de ONG e de movimentos sociais insiste na melhora considerável da situação e no cumprimento de muitas promessas estatais. É assim questionada a realização de reformas como a prescrição de zoneamento do plantio da cana-de-açúcar para a proteção de biomas ameaçados, reformas essas anunciadas pela ministra do Meio Ambiente, consciente dos problemas, mas infelizmente sem força política e que renunciou ao cargo em abril de 2008. No entanto, há exemplos positivos: em São Paulo, uma comissão deverá impedir o avanço do plantio da cana-de-açúcar em áreas ecologicamente protegidas. Nos municípios de Rio Verde, em Goiás, e em Dourados, em Mato Grosso do Sul, já foi estipulada área máxima de plantio (em \%) da cana-de-açúcar em regiões determinadas para a agricultura. ${ }^{10}$

Em Piracicaba e Ribeirão Preto, do etanol, nos últimos anos, concentramse atividades de nível internacional, pouco percebidas na Europa. Especialmente Piracicaba desenvolveu-se como um cluster de conhecimento e tecnologia no setor do etanol, enquanto, em Ribeirão Preto, estão as maiores fazendas de cana-de-açúcar e usinas que apresentam a melhor qualidade de solos. Em Piracicaba, localizam-se a universidade (Esalq/USP), contando com diversos grupos de pesquisa nos mais diversos setores, e o Centro de Tecnologia Canavieira (CTC), contando com parceiros internacionais de renome. Também em Piracicaba, que se desenvolveu muito nas últimas duas décadas (Santos, 2007), está sediada a matriz do maior produtor de etanol no Brasil, a Cosan, além de muitas empresas produtoras de insumos agrários, empresas de consultoria, cooperativas, peritos em assuntos agrários, lobistas dos diversos setores e muitas indústrias do setor de máquinas agrícolas e de instalações para destilarias, como a Dedini. 


\section{Produção de biodiesel: o boom da soja contra o plantio da mamona por pequenos produtores?}

O plantio da soja no Brasil não somente está ligado à expansão intrarregional das áreas cultivadas, mas sobretudo a um grande deslocamento de áreas centrais de plantio. Das áreas de plantio de pequenos colonos - descendentes de imigrantes europeus sediados nas florestas subtropicais do Rio Grande do Sul (Pfeifer \& Kohlhepp, 1966; Lücker, 1986) -, a fronteira do plantio da soja deslocou-se, no final dos anos 1960, para o norte do Paraná - onde a soja era plantada em substituição ao café que havia sido erradicado por causa das geadas (Kohlhepp, 1975). A frente da soja foi assim deslocada para o norte nos campos cerrados semiúmidos do Planalto Central (Coy \& Lücker, 1993) (Figura 4).

Esse deslocamento do plantio da soja foi realizado pelos fazendeiros do sul do Brasil que conseguiram comprar terras a preço baixo, outrora exploradas pela pecuária extensiva, transformando-as em agricultura moderna e fazendas muito produtivas. Essa mudança da estrutura agrícola e colonização dos campos cerrados somente pôde ser realizada com apoio de programas estatais de incentivo (Proterra, Polocentro, Prodecer) e é um dos fenômenos destacados do desenvolvimento agrário no Brasil. Sobretudo em Mato Grosso - o novo "Eldorado", com cidades pioneiras (Coy, 1992) economicamente bem-sucedidas e com boa infraestrutura (Veja, 23.7.2008), como a cidade de Sorriso - onde, no início dos anos 1980, foi desenvolvido o complexo agroindustrial da soja (plantio da soja, moinho da soja, usina de óleo de soja, produção de pellets, comércio de produtos agroquímicos, consultoria agrária, bancos de crédito, infraestrutura de transporte, capacidade de armazenamento), conseguindo sobreviver no centro-oeste apesar das diversas crises do preço do produto (Kohlhepp \& Blumenschein, 2000).

Por meio da mobilidade espacial e da ascensão dos colonizadores do sul do Brasil, surgiu uma nova elite - não pecuarista - em Mato Grosso que não somente criou um novo paradigma técnico-econômico do complexo da soja (Blumenschein, 2001) no setor agrário, mas também provocou conflitos socioculturais na população mato-grossense tradicional, levando finalmente à mudança da liderança política do Estado. Blairro Maggi, migrante do sul do país, é hoje governador de Mato Grosso e chamado "o rei da soja" do Brasil. Maggi construiu novas rodovias na região e aumentou a área de plantio, abrindo novos caminhos para o comércio em razão da crescente produção regional da soja. Paralelamente à "frente da soja", com base em sementes geneticamente modificadas, avançou para a região sul das florestas tropicais da Amazônia, sendo assim responsabilizado pela destruição das matas (Fearnside, 2001; Coy, 2003; USDA, 2004; GI, 2006; Kohlhepp, 2002, 2007).

No âmbito do abrangente programa de desenvolvimento "Avança Brasil", o governo federal apoiou a reorientação para o Norte dos caminhos de transporte e portos de transbordo para a exportação da soja para a Europa, dando forte impulso à produção regional da soja na parte central do país (38\% da produção brasileira). Vinte e sete por cento da área total de plantio da soja encontram-se 
na região de planejamento "Amazônia Legal”, dos quais 90\% em Mato Grosso. ${ }^{11}$ Um quarto da área da soja de Mato Grosso estende-se em áreas desmatadas, outrora florestas tropicais (GI, 2006). Os fazendeiros da soja no Pará, no Tocantins e no Maranhão já usufruem das possibilidades espaciais para a expansão do plantio da soja. Foram criados portos fluviais de boa qualidade visando à exportação da soja para ultramar, em Itacoatiara, no Rio Amazonas, que recebe mercadorias de Porto Velho através do Rio Madeira e Santarém. A concessão à empresa Cargill para a continuação da obra do porto em Santarém - final da discutida estrada BR-163 Cuiabá-Santarém - não teve aprovação quanto à Eia/Rima e é tida como ilegal pelos tribunais brasileiros.

Sob pressão dos grupos não governamentais de meio ambiente, as federações de empresários das indústrias de óleos vegetais e dos exportadores decidiram não mais comprar soja de novas plantações na Amazônia. Essa moratória, no momento, difícil de ser examinada, tem validade de dois anos e já foi prorrogada. Durante esse período, as diretrizes da lei florestal devem ser observadas e novas estratégias deverão ser decididas.

As multinacionais de agrobusiness, como a Cargill, ADM e Bunge, agem com fornecimento cada vez maior de sementes geneticamente modificadas, como o "Roundup-Ready" tolerável aos herbicidas, defensivo do produtor de sementes Monsanto afinado com agroquímicos, como também com componentes de produção, capacidade de armazenamento, expansão da infraestrutura e estratégias de marketing. Elas são responsáveis por $60 \%$ do financiamento da produção da soja no Brasil (GI, 2006).

No âmbito da "Campanha para um Brasil livre de genética modificada", uma série de ONG conseguiu, em 1998, evitar por ordem judicial a liberação da soja transgênica, com o apoio do antigo Partido dos Trabalhadores (PT). O governo Lula, desde 2003 no poder, decretou, no seu primeiro ano de gestão, uma "medida provisória", muito discutida, liberando o plantio da soja geneticamente modificada como regulamentação excepcional - sob protesto da então ministra do Meio Ambiente e de diversos grupos ambientalistas. Essa decisão, tomada sem que tivesse sido feita análise de risco e sob pressão do lobby agrário nacional e internacional, mostra que o governo PT assumiu totalmente o modelo econômico bem-sucedido do agrobusiness. Isso contribuiu para que a soja transgênica, estimada em 8\% da produção nacional em 2002/2003 (Kohlhepp, 2003b), aumentasse consideravelmente até os dias de hoje.

Os maiores lucros são, sobretudo, dos produtores de sementes e oriundos de taxas de licenças que foram, em 2004, e somente no Rio Grande do Sul, maiores que o orçamento do Estado para todo o setor agrário. Sementes transgênicas e herbicidas são mais caros que os produtos convencionais. Mesmo a produtividade de soja sendo menor (Rehaag, 2007), a agricultura contratual é mais segura, e a proteção das plantas, mais fácil. Segundo Duarte (2005), em 2004 o governo federal aumentou em 50 vezes o valor limite tolerado de resíduos de herbicidas 
(Glyphosat) na soja, cujo valor anterior tinha sido estipulado em 1985. Com isso, o Brasil perdeu sua posição especial que o diferenciava dos países plantadores de soja transgênica, como os Estados Unidos, a Argentina e o Paraguai. No Brasil, a produção da soja duplicou em 15 anos para 60 milhões de toneladas (Figura 2), é hoje o segundo maior produtor de soja, depois dos Estados Unidos - sendo, no entanto, o maior exportador do produto.

Depois da crise do BSE, o mercado de produção de ração na União Europeia viu-se obrigado a produzir ração à base de vegetal, rica em proteína, em substituição à ração animal. Com isso, haverá ainda maior demanda do produto, especialmente em forma de pellets. Não esquecendo que a China importa do Brasil $40 \%$ da sua demanda de produtos de soja.

O plantio da soja destina-se quase que totalmente à produção de ração e de óleo vegetal, mas, no âmbito da discussão sobre biocombustíveis, a produção de biodiesel extraído de óleos vegetais está no foco dos interesses - paralelamente à produção de etanol da cana-de-açúcar. Isso porque $90 \%$ da produção atual de biodiesel (2007: 962 milhões de litros) são produzidos da soja. Além disso, há soja à disposição em todas as regiões do país - juntamente com o óleo de dendê e o de babaçu no Norte e no Nordeste (Pará, Maranhão, Bahia), como também a mamona na Bahia, o algodão e o girassol no Sudeste e no Centro-Oeste.

Em 2004, o governo brasileiro iniciou o Programa Nacional de Produção do Biodiesel (PNPB). O biodiesel pode substituir, em parte ou totalmente, o diesel mineral para veículos leves, caminhões, tratores e geradores (mistura 2\%-5\%). A mistura de biodiesel no Brasil é legalmente estabelecida desde 2008. Primeiramente, a mistura obrigatória era de $2 \%$ e, pouco a pouco, será elevada a $5 \%$ em 2010 , o que corresponderia a uma produção de 2,4 bilhões de litros. Segundo informação do Ministério da Agricultura, o biodiesel puro, à base de soja, é capaz de concorrer com o preço de 60 US\$/ barril de petróleo. A mamona - com 705 litros/ha - e a palmeira de dendê com 5.000 litros/ha - têm um rendimento muito maior do que a soja, com rendimento de 400 litros/ha (Embaixada do Brasil, 2007).

O PNPB valoriza especialmente a participação de pequenos produtores de mamona no Nordeste e de óleo de dendê no Norte. Isso significa inclusão social, consideração da realidade ecológica, mas também exige a garantia de qualidade e a capacidade à competição. Os produtores de biodiesel que dispõem de quotas previamente definidas e regionalmente diferenciadas de matéria-prima dos pequenos colonos recebem o "Selo Combustível Social" e descontos tributários. Para os pequenos agricultores do Nordeste, isso poderia significar um grande apoio em razão da garantia de mercado receptor. Essa agricultura contratual, no entanto, pode levar a maior dependência e a preços baixos, quando a autonomia do produtor é falsa (Kobra, 2008a). Além disso, o risco das condições climáticas e da safra fica por conta dos pequenos produtores.

Não se sabe se a esperada expansão do plantio da mamona e as condições técnicas de produção poderão ser alcançadas com fornecimento contínuo e em médio prazo das quantidades necessárias de matéria-prima. Peritos brasileiros, 
como da Esalq/USP, em Piracicaba, ainda não estão convencidos do sucesso dessa produção. Segundo análises da Agência Nacional de Petróleo (ANP) e da Empresa Brasileira de Pesquisa Agropecuária (Embrapa), não é possível o uso exclusivo do óleo de rícino em motores movidos a diesel em razão de sua alta densidade e viscosidade, como também não é apropriado para a produção de biodiesel ( $A H K$ Câmara Brasil-Alemanha, WB 28, 28.7.2008). Isso significaria que o apoio aos pequenos produtores, pelo qual o governo faria jus à sua responsabilidade político-social, seria somente parcialmente realizável.

Vale mencionar a instalação de uma cooperativa de biocombustível no Rio Grande do Sul, organizada, em 2005, pelo Movimento de Pequenos Agricultores (MPA) e pelo MST, abrangendo 25 mil famílias em 62 municípios no noroeste do Estado. Nessa região, usam-se a mamona e o girassol como matérias-primas, e o plantio é feito pela rotação de culturas e sem o emprego de pesticidas (Noronha \& Ortíz, 2006). O projeto-modelo "Brasil Ecodiesel" - com plantio de mamona - é feito no Piauí com apoio financeiro da Alemanha. Não é garantido se a produção de biodiesel à base dessa matéria-prima pode ser realmente uma opção econômica satisfatória (Giersdorf \& Nitsch, 2006). ${ }^{12}$ Sem abrangente apoio estatal, os objetivos de produção dificilmente poderão ser alcançados em razão da pressão do agrobusiness, de obstáculos burocráticos e de eventuais problemas tecnológicos.

Quanto à produção de biodiesel da soja, que depende dos preços do mercado mundial para a exportação de seus produtos, há áreas suficientes de plantio, ${ }^{13}$ bem como quantidade de produção à disposição (Figura 2). Em razão das sementes novas, as condições apropriadas para o plantio nas regiões de ecossistemas tropicais úmidos foram espacialmente bem expandidas. Por esse motivo, a crescente devastação de florestas na Amazônia está ligada à produção de biodiesel por causa da expansão das área de plantio da soja (Fearnside, 2001; GI, 2006; Kohlhepp, 2007). O país dispõe de áreas dos estabelecimentos agropecuários de 257 milhões de hectares, sem contar as áreas de floresta dentro de propriedades, e dispõe de pecuária extensiva na região dos campos cerrados no Brasil Central, cujos pastos poderiam ser melhorados e aumentado o número de gado por hectare. O governo frequentemente chama isso de "reserva" para o agrobusiness, tanto para o plantio da soja como para o plantio da cana-de-açúcar. A produção da soja já se concentra nitidamente na região dos campos cerrados.

No que se refere à sustentabilidade na produção de biodiesel, há certas reservas do ponto de vista ecológico e social quanto ao uso da soja como matériaprima: plantio de monoculturas por latifundiários, concentração de propriedades e opressão maciça contra pequenos produtores e inúmeros conflitos de terra, uso exagerado de agroquímicos e consequente contaminação da água, alta mecanização e pouca demanda de mão de obra (2 trabalhadores/100 ha), bem como competição pelo uso do solo com os produtores de gêneros alimentícios básicos.

Esses problemas são alertados por cientistas e pelo MST. Por meio de ações duvidosas de protesto, por ocupação de fazendas e de prédios de instituições estatais como outras ações de grande efeito público, o grupo protesta contra a política 
agrária do governo - orientada cada vez mais para o agrobusiness - e contra a falta de quaisquer princípios sistemáticos para a realização da tão desejada reforma agrária.

Do ponto de vista positivo do meio ambiente, o uso do biodiesel apresenta diminuição de monóxido de carbono em 48\% e 67\% de hidrogênio carburado. No entanto, os presentes dados são relativados durante todo o processo da produção do biodiesel, fazendo que o balanço ecológico desse produto não seja positivo.

\section{Conclusões e perspectivas}

Depois das decisões do Protocolo de Kyoto em 1997 e dos recentes relatórios do "Intergovernmental Panel of Climate Change" em 2007, reforçaramse, em todo o mundo, as discussões sobre o crescente efeito estufa e a grande necessidade de rápida redução de $\mathrm{CO}_{2}$. Governos de muitos países não somente estipularam valores-limite para a diminuição de emissões de gases das energias fósseis, mas também conduziram a substituição por energias renováveis a um tema principal. Não somente os países industrializados querem e devem diminuir a sua dependência do petróleo, mas especialmente os países emergentes e em desenvolvimento tentam aproveitar as suas condições naturais na produção própria de energias renováveis à base de matérias-primas vegetais.

Nas energias renováveis e em seu uso no transporte, os biocombustíveis assumem papel especial, pois estão ligados diretamente aos objetivos modernos do desenvolvimento sustentável. Recentemente, essa sustentabilidade quanto à redução de $\mathrm{CO}_{2}$ vem sendo questionada também em relação ao etanol à base de canade-açúcar, ao qual era atribuído melhor ecobalanço. Um estudo da OCDE (2008), no entanto, ressalta que os gases estufa pelo uso de etanol da cana-de-açúcar são excepcionalmente reduzidos de $70 \%$ a $90 \%$, comparado com o uso da gasolina. Observa-se que a redução desses gases no uso do etanol é bastante menor quando produzido do milho (20\%-50\%), da beterraba (30\%-50\%) e do trigo (30\%-60\%).

A posição do etanol certamente será reforçada, quando, em 2010, a União Europeia implementar a taxa de impostos calculada a partir da emissão de $\mathrm{CO}_{2} \mathrm{de}$ veículos.

O exemplo no Brasil mostra que a produção de biodiesel à base de soja não cumpre as normas de sustentabilidade. As abrangentes ações das empresas agrícolas que querem introduzir cada vez mais produtos agrícolas geneticamente modificados no Brasil, juntamente com produtores de sementes e de agrodefensivos, intensificam os problemas fundamentais da estrutura agrária (Kohlhepp, 1994). O atual governo brasileiro, também eleito por causa de reformas sociais anunciadas, atribui a economia bem-sucedida e o aumento do lucro esperado da exportação de biocombustíveis à rede transnacional de agrobusiness, que se deixa levar pela euforia de visões futuras otimistas e proclama o Brasil como a potência mundial das energias renováveis do século XXI, como também é frequentemente mencionado pelo presidente Lula (Silva, 2007). 
Nos atuais processos de desenvolvimento na produção de biocombustíveis no Brasil, faltam componentes sociais e ecológicos, com exceção da produção de etanol em São Paulo. Mas, sob pressão da expansão de monoculturas, com grande concentração de terras e crescente aumento dos preços da terra, parece que a fragilidade dos pequenos produtores (Neuburger, 2000) não é considerada, tampouco a garantia de alimentos e a fragilidade dos ecossistemas com contaminações excessivas do meio ambiente. É comprovado que a homogeneização da paisagem agrária leva ao esvaziamento do espaço rural e fortifica a migração dos excluídos ao circuito da pobreza urbana.

Os cenários de exportação do etanol ainda se encontram ligados a aspectos político-econômicos imponderáveis, sobretudo porque a União Europeia (UE) não está firme no seu propósito de aumentar a parte do etanol da gasolina a $10 \%$ até 2020. Ainda não é possível obter uma avaliação fundamentada da produção de biodiesel, sendo essa recente e atendendo somente ao mercado nacional. Para o Brasil, o aumento do lucro pela exportação de biocombustíveis, isto é, do etanol, é muito importante. Não há ainda confirmação concreta dos global players quanto à proteção aos produtores nos Estados Unidos e na UE, pelas altas taxas de importação. Em julho de 2008, na rodada Doha da Organização Mundial de Comércio, o etanol não constava da lista de produtos ambientais privilegiados na taxação, sob protesto do Brasil que reivindica o livre acesso do produto a todos os mercados. Além disso e, de acordo com afirmação do então candidato a presidência dos Estados Unidos, Barack Obama, "não vale a pena substituir nossa dependência do petróleo pela dependência do etanol do Brasil" (Veja, 2.7.2008). Por sua vez, o Japão mostra interesse em importar etanol do Brasil, o que já é feito pela Holanda e Suécia.

No âmbito da cooperação Sul-Sul, o Brasil ocupa posição de destaque pela transferência de know-how brasileiro na produção de etanol a países dependentes da importação do petróleo. Por meio disso a importância da política externa do Brasil poderia ser ainda mais acentuada.

Nos setores do meio ambiente e da política agrária, o governo brasileiro tem que ser bem-sucedido no impedimento do avanço das monoculturas na Região Amazônica e no Pantanal, mediante sistema de zoneamento agroecológico, discutido há anos. Considerando os altos lucros na exportação, poderia ser instituído programa de incentivo na agricultura de pequenos produtores, além do existente, pois a participação na produção de matérias-primas vegetais e de biocombustíveis é possível nas pequenas destilarias, quando apoiadas por cooperativas bem organizadas.

O controle de quotas na produção de biodiesel deve ser garantido para evitar o domínio total pelos lobistas da soja nesse setor, e é necessária melhor integração dos produtores de mamona no processo geral. Condições de trabalho, salário condizente e critérios de meio ambiente - o que é do conhecimento dos produtores - devem ser rigorosamente controlados também no plantio da cana- 
de-açúcar. A rápida concessão de selo social e de meio ambiente pode colocar a sustentabilidade em risco.

O aumento positivo, quantitativo e econômico da produção e da produtividade como o aumento de exportação deve se basear em melhoria de qualidade das condições sociais e ecológicas. Na situação rural de hoje, dominada por conflitos que, em algumas regiões, provocam ações quase que incontroláveis, a euforia sobre biocombustíveis e o modelo atual de exportação do agrobusiness não estão conforme com o urgente desenvolvimento sustentável da região rural, anunciado pelo governo. A política heterogênea de coalizões partidárias continua provocando bloqueios de reformas em razão do longo tempo de negociações (Boeckh, 2003).

O futuro está na produção de biocombustíveis da segunda geração, a partir da próxima década, quando o etanol será produzido de bagaço, celulose e outras matérias orgânicas, e a produtividade poderá ser aumentada de 40\%-50\%. Essa produção de segunda geração estará em harmonia com o meio ambiente e iniciará "uma civilização moderna de biomassa" (Sachs, 2005). Assim, a pressão pelo uso da terra e os conflitos de interesse ligados com a produção de biocombustíveis certamente serão diminuídos, dando chance a uma reforma agrária bem concebida, assegurando tanto o trabalho de pequenos agricultores como a alta biodiversidade.

Melhoramentos para o cumprimento dos critérios sociais e de meio ambiente podem ser uma grande chance para o Brasil, como na venda de etanol no mercado mundial. Na Europa e nos Estados Unidos, esses critérios não podem ser usados para proteger seus próprios produtores da concorrência barata internacional. Isso poderá funcionar quando os países industrializados se afastarem da política de protecionismo e de incentivos para a bioenergia - como reivindicação do economista da FAO (Schmidhuber, 2008) e da OCDE (2008). No âmbito da discussão da proteção ao clima, deve persistir a constatação de que, no trânsito, somente o etanol à base da cana-de-açúcar poderá realmente contribuir para a redução substancial das emissões de $\mathrm{CO}_{2}$, até o amadurecimento técnico e o uso em massa, no futuro, dos motores elétricos e movidos a hidrogênio.

Na Feira Internacional de Automóveis em Frankfurt em 2009, entretanto, os carros híbridos, movidos a eletromotores e gasolina, e protótipos de carros com eletromotores chamaram muito mais atenção do que carros com motores flex-fuel. Obviamente os biocombustíveis da primeira geração, como etanol da cana-de-acúcar, são vistos na Europa e na Ásia como uma tecnologia de transição cuja época já terminou antes mesmo de ter sido usada nos automóveis nesses continentes.

\section{Notas}

1 Disponível em: <http://www.anfavea.com.br>. Acesso em: 20 mar. 2008.

2 Disponível em: <http://www.unica.com.br $>$; $<$ http://www.ibge.gov.br $>$. Acesso em: 16 mar. 2008. 
3 Disponível em: <http://www.iea.sp.gov.br>. Acesso em: 18 mar. 2008.

4 Disponível em: <http://www.iea.sp.gov.br>. Acesso em: 14 mar. 2009.

5 Disponível em: <http://www.ibge.gov.br>. Acesso em: 28 jul. 2008. Disponível em: <http://www.ipeadata.gov.br>. Acesso em: 14 ago. 2009.

6 Disponível em: <http://www.bbc.co.uk>. Acesso em: 9 jul. 2008.

7 Disponível em: <http://www.comciencia.br/comciencia/?section=8\&edicao=23\&i d=255>. Acesso em: 8 set. 2007.

8 Disponível em: <http://www.ircamericas.org/esp/4329>. Acesso em: 24 set. 2007.

9 Disponível em: <http://www.unica.com.br>. Acesso em: 13 mar. 2008.

10 Disponível em: <http://www.tierramerica.info/nota.php?lang=esp\&idnews=1285>. Acesso em: 24 set. 2007. Disponível em: <http://www.ethanolbrasil.blogspot. com/2007/09>. Acesso em: 25 set. 2007.

11 Disponível em: <http://www.ibge.gov.br>. Acesso em: 13 mar. 2008.

12 Disponível em: <http://www.brasilecodiesel.com.br>. Acesso em: 13 mar. 2008.

13 Disponível em: <http://www.plataformasoja.org.br>. Acesso em: 13 mar. 2008.

\section{Referências}

APLA. Brazilian market. Ethanol. Piracicaba, 2008. (CD-R).

BERTRAND, J.-P. et al. Le contexte agricole des biocarburants au Brésil. Rumbos, Université Toulouse-le-Mirail, 8.9.2007. Disponível em: <http://www.univ-tlse2.fr/ amlat/gral/index.htm; via>.

. La politique brésilienne des carburants d’origine végétale: le pari sur l’éthanol. Rumbos, Université Toulouse-le-Mirail, 12.3.2008. Disponível em: <http://www. univ-tlse2.fr/amlat/gral/index.htm>.

BLUMENSCHEIN, M. Landnutzungsveränderungen in der modernisierten Landwirtschaft in Mato Grosso, Brasilien. Tübingen: Tübinger Beiträge zur Geographischen Lateinamerika-Forschung 21, 2001.

BOECKH, A. Der gefesselte Gigant: Politik und Reform(un)fähigkeit in Brasilien. In: KOHLHEPP, G. (Ed.) Brasilien. s. 1.: s. n., 2003. p.57-80.

BORGES, U. et al. Proálcool. Analyse und Evaluierung des brasilianischen Biotreibstoffprogramms. Saarbrücken / Fort Lauderdale, 1984.

COY, M. Pioneer front and urban development. Social and economic differentiation of pioneer towns in Northern Mato Grosso (Brazil). Applied Geography and Development, v.39, p.7-29, 1992

. Regionalentwicklung im südwestlichen Amazonien. Sozial-und wirtschaftsräumlicher Wandel an der brasilianischen Peripherie zwischen Globalisierung und Nachhaltigkeit. In: KOHLHEPP, G. (Ed.) Brasilien. s. 1.: s. n., 2003. p.215-38.

COY, M.; LÜCKER, R. Der brasilianische Mittelwesten. Wirtschafts-und sozialgeographischer Wandel eines peripheren Agrarraums. Tübingen: Tübinger Beiträge zur Geographischen Lateinamerika-Forschung 9, 1993. 
DUARTE, E. Comissão de meio ambiente e desenvolvimento sustentável. Projeto de decreto legislativo n.499, de 2003, 2005. Disponível em: <http://www.camara.gov.br/ sileg/integras/322640.pdf>.

EMBAIXADA DO BRASIL. Biokraftstoffe in Brasilien. Berlin, 2007.

FATHEUER, T. Mit Agrotreibstoffen aus Brasilien gegen den Klimawandel? Berlin, 2007.

FEARNSIDE, P. M. Soybean cultivation as a threat to the environment in Brazil. Environmental Conservation, v.28, n.1, p.23-38, 2001.

FRITZ, T. Agroenergie in Lateinamerika. Fallstudie anhand vier ansgewählter Länder: Brasilien, Argentinien, Paraguay, Kolumbien. Stuttgart, 2008. (versão preliminar).

GEOMAPAS. Usinas de etanol e açúcar das regiões Centro-Sul e Norte/Nordeste 2007. São Paulo, 2008. (mapa).

GIERSDORF, J.; NITSCH, M. Biodiesel in Brasilien - ein neues Proálcool oder Chance für den Nordosten? Focus Brasilien, Rio de Janeiro, n.1, 2006.

GREENPEACE INTERNATIONAL (GI). Eating up the Amazon. 2006. Disponível em: <http://www.greenpeace.org/raw/content/international/press/reports/eatingup-the amazon.pdf>.

KENFIELD, I. Brazil's ethanol plan breeds rural poverty, environmental degradation. In:InternationalRelations Center. 2007. Disponível em: <http://www.americas.irconline.org/am/4049>.

KERSAINT, M. Brasilien - das Saudi-Arabien des 21. Jahrhunderts? Nachhaltige Entwicklung durch Substitution von Rohöl durch Biotreibstoffe für Automobile. Reutlingen, 2007. Tese de diploma (inédita) - European School of Business.

KOBRA (Cooperação Brasil). Sonderheft zu Agrotreibstoffen. Brasilicum, Freiburg i. Br., n.160, junho 2007.

. Brasilicum, Freiburg i. Br., n.170, maio 2008a.

. Rundbrief, Freiburg i. Br., n.196, maio/junho 2008b.

KOHLHEPP, G. Agrarkolonisation in Nord-Paraná. Wirtschafts- und sozialgeographische Entwicklungsprozesse einer randtropischen Pionierzone Brasiliens unter dem Einfluss des Kaffeeanbaus. Wiesbaden, 1975. (Heidelberger Geographische Arbeiten 41).

Ocupação e valorização econômica da Amazônia. Estratégias de desenvolvimento do governo brasileiro e empresas privadas. Revista Geográfica, México, n.94, p.67-88, 1981 .

. Interessenkonflikte in der lateinamerikanischen Agrarproduktion. Grundnahrungsmittelerzeugung contra Energiepflanzenanbau und Exportproduktion. Mitteilungen der Geographischen Gesellschaft München, München, n.68, p.141-73, 1983.

. Amazonien. Regionalentwicklung im Spannungsfeld ökonomischer Interessen sowie sozialer und ökologischer Notwendigkeiten. Köln, 1987. (Problemräume der Welt $8)$.

. Strukturprobleme des brasilianischen Agrarsektors. In: BRIESEMEISTER, D. et al. (Ed.) Brasilien heute. Frankfurt am Main: s. n., 1994. p.277-92.

. (Ed.) Mensch-Umwelt-Beziehungen in der Pantanal-Region von Mato Grosso/ 
Brasilien. Beiträge zur angewandten geographischen Umweltforschung. Tübingen: Tübinger Beiträge zur Geographischen Lateinamerika-Forschung 12, 1995.

KOHLHEPP, G. Conflitos de interesse no ordenamento territorial da Amazônia brasileira. Estudos Avançados, São Paulo, v.16, n.45, p.37-61, 2002.

(Ed.) Brasilien - Entwicklungsland oder tropische Großmacht des 21. Jahrhunderts? Tübingen: s. n., 2003a.

Brasilien - Schwellenland und wirtschaftliche Führungsmacht in Lateinamerika. In: KOHLHEPP, G. (Ed.) Brasilien. s. 1.: s. n., 2003b. p.13-55.

Desenvolvimento regional na Amazônia Brasileira. Estratégias de ordenamento territorial e conflitos entre interesses econômicos e uso sustentável dos recursos naturais nas florestas tropicais. In: PASSOS, M. M. dos. BR-163-De estrada dos colonos a corredor de exportação. Maringá: s. n., 2007. p.15-62.

. Biokraftstoffe im Fokus des Agrobusiness in Brasilien. In: GRAF, P.; STEHNKEN, T. (Ed.) Lateinamerika. Politik, Wirtschaft und Gesellschaft. BadenBaden: s. n., 2008. p.135-57. (Weltregionen im Wandel 3).

KOHLHEPP, G.; BLUMENSCHEIN, M. Brasileiros sulistas como atores da transformação rural no Centro-Oeste brasileiro: o caso de Mato Grosso. Território, Rio de Janeiro, n.8, p.47-66, 2000.

LÜCKER, R. Agrarräumliche Entwicklungsprozesse im Alto-Uruguai-Gebiet, Südbrasilien. Tübingen: Tübinger Beiträge zur Geographischen Lateinamerika-Forschung 2, 1986.

MACEDO, I. de C. (Org.) Sugar cane's energy. Twelve studies on Brazilian sugar cane agribusiness and its sustainability. São Paulo: s. n, 2005.

Situação atual e perspectivas do etanol. Estudos Avançados, São Paulo, v.21, n.59, p.157-65, 2007.

MINISTÉRIO DE MINAS E ENERGIA (MME). Diretrizes de política de agroenergia 2006-2011. 2006. Disponível em: <http://www.mme.gov.br>. Acesso em: 28 jul. 2008.

Brazilian Energy Balance 2007. Year 2006. Rio de Janeiro, 2007.

MOREIRA, J. R.; GOLDEMBERG, J. The alcool program. Energy Policy, n.27, p.229$45,1999$.

MILDNER, S.; ZILLA, C. Brasilien und Biokraftstoffe. SWP-Aktuell, v.60, p.1-4, 2007.

NEUBURGER, M. Kleinbäuerliche Verwundbarkeit in degradierten Räumen. Überlegungen zur Politischen Ökologie der Pionierfrontentwicklung in Brasilien. Geographische Zeitschrift, v.88, n.1, p.21-35, 2000.

NEUE ZÜRICHER ZEITUNG. 14 - 15.6.2008.

NOLTE, D.; STOLTE, C. Machtressource Bioenergie: Eine neue strategische Partnerschaft zwischen Brasilien und den USA. GIGA Focus, n.3, p.1-8, 2007.

NORONHA, S.; ORTÍZ, L. Agribusiness and biofuels: an explosive mixture - Impacts of monoculture expansion on the production of bioenergy, Rio de Janeiro. 2006. Disponível em: <http://www.fboms.org.br/gtenergia/energia.htm>. 
OCDE. Economic assessment of biofuel support policies. Paris, 2008.

OLIVÉRIO, J. L. Brazilian sugar cane sector - evolution, trends, sustainability. São Paulo, 2008. (CD-R).

PFEIFER, G.; KOHLHEPP, G. Wirtschafts- und sozialgeographische Studien in Südbrasilien. Heidelberg: Forschungsbericht, 1966. (inédito).

REHAAG, R. Die Weichen sind gestellt. Brasilien auf dem Weg in die transgene Landwirtschaft. In: Rohstoffboom mit Risiken. Jahrbuch Lateinamerika. Analysen und Berichte 31. Münster, 2007. p.115-26.

SACHS, I. Da civilização do petróleo a uma nova civilização verde. Estudos Avançados, São Paulo, v.19, n.55, p.197-214, 2005.

SANTOS, J. R. dos. (Org.) Agenda 21 de Piracicaba. Piracicaba, 2007.

SCHMIDHUBER, J. Die Industriestaaten sollten die Bioenergie nicht fördern. Neue Zürcher Zeitung, 107, p.30, 9.5.2008.

SILVA, L. I. L. da. Globales Regieren: Die Herausforderung der nachhaltigen Entwicklung und die Rolle der Biotreibstoffe. In: WÜRTELE, G. (Ed.) Machtworte. Wirtschaftslenker und Staatsmänner stellen sich den Fragen der Zukunft. Frankfurt am Main: s. n., 2007. p.59-70.

SMEETS, E. et al. Sustainability of Brazilian bio-ethanol. Utrecht, 2006.

SUHR, H. Zwischen Überfluss und Engpässen: Brasiliens Energiesektor in Bewegung. KAS / Auslandsinformationen 2/08, p.55-83, 2008.

THÉRY, H. La vague déferlante du soja brésilien. Mappemonde, v.74, n.2, p.1-4, 2004. Disponível em: <http://www.mappemonde.mgm.fr/num2/articles/art04204.html>.

UNICA. Produção e uso do etanol combustivel no Brasil. São Paulo, 2007. Disponível em: <http://www.unica.com.br>.

USDA. The Amazon: Brazil's final soybean frontier. 2004. Disponível em: <http:// www.fas.usda.gov/pecad/highlights/2004/01Amazon_soybeans.htm>.

WORLDWATCH INSTITUTE (Ed.) Biofuels for transportation. Global potential and implications for sustainable agriculture and energy in the $21^{\text {st }}$ century. Washington: $s$. n., 2006.

XAVIER, M. The Brazilian sugarcane ethanol experience. Issue analysis 3, Washington, DC, 2007. Disponível em: <http://www.cei.org/pdf/5774.pdf>.

RESUMO - Um dos objetivos da política energética é a redução das emissões de $\mathrm{CO}_{2}$. Os biocombustíveis são uma das alternativas para o setor de transportes. O Brasil é o líder na produção de etanol extraído da cana-de-açúcar. Os preconceitos existentes nos Estados Unidos e na Europa com relação à importação do etanol brasileiro não têm fundamento, pois esse produto apresenta o melhor balanço ecológico e não diminui a produção de gêneros alimentícios. Na produção de biodiesel à base de soja, os preconceitos são, em parte, justificados. Quanto ao etanol, os países industrializados não 
deveriam usar critérios exagerados à sustentabilidade da produção como pretexto para proteger seus próprios produtores contra a importação de produtos brasileiros com preço mais competidor.

PALAVRAS-CHAVE: Energias renováveis, Biocombustíveis, Etanol, Biodiesel, Sustentabilidade.

ABSTRACT - One of the aims of energy policies is reducing $\mathrm{CO}_{2}$ emissions. In transports bio-fuels are one of the alternatives. Brazil is the world leader in producing ethanol from sugar cane. Prejudice against imports of Brazilian ethanol in US and EU markets is unjustified, as it represents the best ecological balance and does not reduce production of basic food in Brazil. As to biodiesel on the basis of soybeans social and ecological reserves partly are in order. Regarding ethanol industrialized countries should not use exaggerated criteria as to sustainability of production as pretext for protecting their own producers from imports of cheaper Brazilian bio-fuels.

KEYWORDS: Renewable energies, Bio-fuels, Ethanol, Biodiesel, Sustainability.

Gerd Kohlhepp é professor emérito da Cátedra de Geografia Econômica e Social da Universidade de Tübingen/ Alemanha. Membro da Academia Brasileira de Ciências. $@$ - gerd.kohlhepp@t-online.de

Recebido em 21.8.2008 e aceito em 29.8.2008. 